IZA DP No. 9613

Does Self-Control Depletion Affect Risk Attitudes?

Holger Gerhardt

Hannah Schildberg-Hörisch

Jana Willrodt

December 2015 


\title{
Does Self-Control Depletion Affect Risk Attitudes?
}

\author{
Holger Gerhardt \\ University of Bonn \\ Hannah Schildberg-Hörisch \\ University of Bonn \\ and IZA \\ Jana Willrodt \\ University of Bonn
}

Discussion Paper No. 9613

December 2015

\author{
IZA \\ P.O. Box 7240 \\ 53072 Bonn \\ Germany \\ Phone: +49-228-3894-0 \\ Fax: +49-228-3894-180 \\ E-mail: iza@iza.org
}

\begin{abstract}
Any opinions expressed here are those of the author(s) and not those of IZA. Research published in this series may include views on policy, but the institute itself takes no institutional policy positions. The IZA research network is committed to the IZA Guiding Principles of Research Integrity.

The Institute for the Study of Labor (IZA) in Bonn is a local and virtual international research center and a place of communication between science, politics and business. IZA is an independent nonprofit organization supported by Deutsche Post Foundation. The center is associated with the University of Bonn and offers a stimulating research environment through its international network, workshops and conferences, data service, project support, research visits and doctoral program. IZA engages in (i) original and internationally competitive research in all fields of labor economics, (ii) development of policy concepts, and (iii) dissemination of research results and concepts to the interested public.
\end{abstract}

IZA Discussion Papers often represent preliminary work and are circulated to encourage discussion. Citation of such a paper should account for its provisional character. A revised version may be available directly from the author. 
IZA Discussion Paper No. 9613

December 2015

\section{ABSTRACT}

\section{Does Self-Control Depletion Affect Risk Attitudes?*}

A core prediction of recent "dual-self" models is that a person's risk attitudes depend on her current level of self-control. While these models have received a lot of attention, empirical studies tailored to testing their core prediction are lacking. Using two prominent models, we derive precise hypotheses for choices between risky monetary payoffs in a state of low selfcontrol, compared to regular self-control; in particular, lower levels of self-control should induce stronger risk aversion for stakes within a particular range. We test the hypotheses in a lab experiment with a large number of subjects $(\mathrm{N}=308)$, using a well-established selfcontrol depletion task and measuring risk attitudes via finely graduated choice lists. While independent manipulation checks document the effectiveness of our depletion task, we do not find any evidence for increased risk aversion after self-control depletion. Our findings have important implications for the future modeling of decision making under risk.

JEL Classification: D03, D81, C91

Keywords: risk attitudes, self-control, ego depletion, dual-self models, experiment

Corresponding author:

Hannah Schildberg-Hörisch

Department of Economics

University of Bonn

Adenauerallee 24-42

53113 Bonn

Germany

E-mail: schildberg-hoerisch@uni-bonn.de

\footnotetext{
* We would like to thank Carlos Alós-Ferrer, Simon Dato, Thomas Dohmen, Armin Falk, Drew Fudenberg, Wilhelm Hofmann, George Loewenstein, Sebastian Schaube, Martin Strobel, Matthias Sutter, and Joël van der Weele, as well as participants of the IMEBESS 2015 conference, the "Motivation, Self-Control, and Economic Behavior" seminar at the University of Cologne, and the MBEES 2015 conference for helpful comments and discussion. Financial support by the German Research Foundation (Deutsche Forschungsgemeinschaft, DFG) through the Collaborative Research Center SFB/TR 15 and the Bonn Graduate School of Economics (BGSE) is gratefully acknowledged. We declare no competing financial interests.
} 


\section{Introduction}

A decision maker's attitude towards risk is a core component of her "economic personality". According to economic theory, risk preferences affect individual decisions whenever outcomes are not deterministic. Empirical evidence documents that risk attitudes are an important predictor of both economic and health outcomes. For instance, a higher willingness to take risks is positively correlated with being self-employed, investing in stocks, and not having insurance, as well as being a smoker, drinking heavily, and being overweight (Anderson and Mellor, 2008; Barsky et al., 1997; Dohmen et al., 2011; Kimball et al., 2008).

Given the central role of risk attitudes in economic theory and their predictive power for individual behavior, a better understanding of factors that potentially influence risk attitudes is of great importance to economists. Inspired by the difficulty of expected-utility theory to explain several empirical phenomena, various recently developed models build on insights from psychology and posit that risk attitudes are shaped by the interaction of "dual selves" (a long-run and a shortrun self; Fudenberg and Levine, 2006, 2011, 2012) or "dual systems" (a deliberative and an affective system, respectively; Loewenstein and O'Donoghue, 2005). In this framework, "self-control" amounts to the long-run self imposing restrictions on the short-run self. Consequently, a crucial determinant of a decision maker's risk attitude is her current level of self-control resources. In particular, the prominent Fudenberg-Levine model predicts that lower levels of self-control induce stronger risk aversion for stakes within a particular range.

In this paper, we first derive three explicit hypotheses on the relationship between self-control and risk preferences, using the model by Fudenberg et al. (2014). Their model is a simplified version of the original Fudenberg-Levine model and specifically addresses decision making under risk in the case of pairwise lottery choice. The hypotheses refer to choices among pairs of two-outcome lotteries, choices among a safe payoff and two-outcome lotteries (all paid out immediately) as well as choices among pairs of two-outcome lotteries that will only be paid out with delay. We adopt a fourth hypothesis directly from Loewenstein and O'Donoghue (2005); their model predicts that self-control depletion leads to more pronounced probability weighting (p. 28). We then test these hypotheses in a laboratory experiment.

The purpose of the experiment is to provide causal evidence on the link between self-control and risk preferences. We exogenously manipulate the level of self-control across treatments using ego depletion, a concept from psychology (Baumeister et al., 1998). In doing so, we also provide sound empirical evidence on the effect of ego depletion on risk attitudes.

Our experiment uses a between-subject design with two conditions. At the beginning, subjects in the treatment group perform a so-called ego depletion task that is well-established in the literature and has been found to induce low selfcontrol in numerous studies (see the meta-analysis by Hagger et al., 2010). Deple- 
tion tasks are based on the notion that the exertion of self-control in one activity consumes self-control resources, thereby increasing self-control costs in subsequent activities (Baumeister et al., 1998). The control group performs a similar, though non-depleting task, i.e., a task that does not reduce self-control resources.

Immediately following the respective task, we obtain precise measures of subjects' risk attitudes. Our measures are based on finely graduated choice lists, one for each of the four hypotheses. Each row of the choice lists consists of a choice between two two-outcome lotteries. Inspired by Eeckhoudt and Schlesinger (2006) and Ebert and Wiesen (2014), we chose one lottery to be a mean-preserving spread of the other, with a sure payoff (a risk premium) being added or subtracted. A noteworthy feature of this method is that it allows quantifying subjects' risk attitudes without assuming a specific utility function. This is particularly important in our case, since the Fudenberg-Levine model contains several functions of unknown parametric form as well as unobservable, difficult-to-estimate quantities.

Contrary to the predictions that we derive from the model by Fudenberg et al. (2014), we do not find any evidence for increased risk aversion after ego depletion. For all of our four choice lists, subjects in the depletion group even exhibit a slight tendency towards less risk-averse choices, compared to the control group. This effect is, however, not statistically significant. Thus, also evidence for increased probability weighting (which would have resulted in lower risk aversion for particular pairwise choices), as predicted by Loewenstein and O'Donoghue (2005), is all but absent.

Since our independent manipulation checks document the effectiveness of our self-control manipulation and since our large sample size $(N=308)$ yields sufficient power to document even small effect sizes, we consider our results to be clean and powerful null findings. Moreover, we find no evidence that subjects behave in a more random manner under depletion. Depleted subjects also do not decide more quickly, as one would expect if they relied on heuristics to a stronger extent. Finally, self-control as a character trait (as opposed to the temporary level of selfcontrol resources) cannot explain heterogeneity of risk attitudes across individuals. Overall, we deem our empirical results on the absence of a link between selfcontrol and risk attitudes informative for the future modeling of decision making under risk.

In principal, we have no doubt that economics can benefit from incorporating psychological concepts in general and self-control in particular. Just as much, we acknowledge the potential of dual-self models to explain behavior in neighboring areas like intertemporal choice and economic theories of addiction. However, different levels of self-control do not seem to induce different risk attitudes. This suggests that risk attitudes and intertemporal choice are less interrelated than the "unified explanation" offered by Fudenberg and Levine (2006) implies.

In general, our paper contributes to a highly active field of research that investigates whether characteristics of the decision environment that go beyond incentives and constraints-such as self-control, cognitive load, emotions, or stress- 
induce systematic, but temporary variations in risk attitudes. ${ }^{1}$ Taking a broader perspective, this line of research challenges the stability of an individual's preferences over time-one of the basic tenets that has shaped economics since Stigler and Becker (1977)'s famous paper, "De Gustibus Non Est Disputandum". In this context, our results on the absence of a causal link between ego depletion and risk attitudes provide evidence on one element of the decision environment by which risk preferences are unaffected; hence, the standard view of stable preferences holds at least with regard to risk preferences and self-control.

Related literature. Traditionally, economics has modeled decision makers without any reference to psychological concepts like "self-control". However, in some cases, the standard models of economic choice-expected-utility theory and the discounted-utility model-have difficulties explaining observed behavior both in the field and in the laboratory. To remedy these problems, numerous theoretical models have been developed recently which capture the notion that some economic decisions may involve a competition between conflicting motives. Resolution of the conflict depends on the use of "self-control" (e.g., Gul and Pesendorfer, 2007; Dekel et al., 2009).

In particular, models involving "multiple selves" or "multiple systems" have become increasingly popular in economics. These "selves" or "systems" are either conceived of as diverging motives held by a decision maker at different points in time (e.g., Laibson, 1997; Diamond and Kőszegi, 2003; Heidhues and Kőszegi, 2009) or as conflicting motives that are present in a decision maker simultaneously (e.g., Loewenstein and O'Donoghue, 2005; Brocas and Carrillo, 2008; Fudenberg and Levine, 2006, 2011, 2012; Fudenberg et al., 2014). While the most common application of these models is temporal discounting, the dual-self model by Fudenberg and Levine $(2006,2011)$ as well as the "dual-system" models by Loewenstein and O'Donoghue (2005) and Mukherjee (2010) also explicitly address decision making under risk.

A particular strength of the model by Fudenberg and Levine is that it offers a "unified explanation" (Fudenberg and Levine, 2006, p. 1449) for several commonly observed discounting-related phenomena such as time inconsistency and risk-related phenomena such as the Rabin paradox ${ }^{2}$ (Rabin, 2000) and the Allais paradox (Allais, 1953). More specifically, a core prediction of the FudenbergLevine model is that lower levels of self-control induce more risk-averse behav-

\footnotetext{
${ }^{1}$ For instance, the results of Cohn et al. (2015), Guiso et al. (2014), Schulreich et al. (2014), and Schulreich et al. (forthcoming) are based on emotional priming and suggest that sadness and fear induce stronger risk aversion. In contrast, the results of Conte et al. (2013) indicate that sadness, fear, anger, and joviality induce risk-seeking behavior. Benjamin et al. (2013) and Deck and Jahedi (2015) find that cognitive load increases risk aversion. Concerning stress, Kandasamy et al. (2014) find that induced stress increases risk-averse behavior, while Buckert et al. (2014) observe stronger risk proclivity for gains, however only for a relatively small subgroup of participants.

${ }^{2}$ This paradox refers to the observation that the levels of small-stakes risk aversion observed in laboratory experiments are too high to be reconciled with behavior for higher stakes when assuming that decision makers care only about final wealth.
} 
ior for stakes within a specific range. However, empirical evidence on this particular relationship between self-control and risk attitudes is scarce. This paper aims at providing the first direct test of a central prediction of the Fudenberg-Levine model.

Fudenberg and Levine (2006, p. 1467), Fudenberg et al. (2014, p. 66), and especially Fudenberg and Levine (2012, p. 3) motivate characteristics of their dual-self model by referring to the so-called "strength model" of self-control. This model was introduced to the psychology literature by Baumeister et al. (1998). The strength model is based on the idea that exerting self-control consumes self-control resources that can be depleted. As a consequence, use of self-control in one task reduces the availability of self-control resources in a subsequent task. This process is referred to as "self-control depletion", "willpower depletion", or "ego depletion" (in analogy to the Freudian ego that controls the $i d$ ). The strength model has also found its way into the economics literature. Not only does it serve as the basis of the models by Fudenberg and Levine (2012) and Ozdenoren et al. (2012); it is also part of the motivation of the analysis of resource allocation in the human brain by Alonso et al. (2014).

The foundations and implications of the strength model of self-control have been empirically investigated by both psychologists and economists numerous times. ${ }^{3}$ Benjamin et al. (2013) provide experimental findings that they interpret as being compatible with "two-systems" models, but emphasize that "there are other possible explanations for [their] results as well" (p. 1252). Concerning the link between ego depletion and decision making under risk, the existing evidence is inconclusive. Moreover, it is not tailored to testing the predictions of the Fudenberg-Levine dual-self model. Using hypothetical choices, De Langhe et al. (2008) observe increased risk aversion following ego depletion. Similarly, Unger and Stahlberg (2011) report that depleted subjects make more risk-averse decisions. In their strongly framed investment experiment, subjects were asked to imagine they were managers making a decision on behalf of their firm which implies that subjects' decisions do not necessarily reflect only their own risk preferences. Kostek and Ashrafioun (2014) examine a setup in which the treatment variation is a combination of ego depletion and prior losses. Under those circumstances, they also find a higher degree of risk aversion. Measuring risk attitudes via choice lists, but with a sample size of only $N=54$, Stojić et al. (2013) find that subjects tend to become more risk-averse under ego depletion-however, not significantly so.

In contrast, two further psychological studies (Bruyneel et al., 2009; Freeman and Muraven, 2010) find increased "risk taking" under ego depletion. Here, however, either (unincentivized) vignettes or tasks with unknown probabilities were used, such that subjects decided under ambiguity instead of risk. ${ }^{4}$ Friehe and

\footnotetext{
${ }^{3}$ See Hagger et al. (2010) for an extensive overview and meta-analysis.

${ }^{4}$ In line with much of the economics literature, we use the term "risky" for a situation in which all payoffs and associated probabilities are known to the decision maker, while we refer to a situation in which at least one of these components is unknown as "ambiguous".
} 
Schildberg-Hörisch (2014) find that depleted subjects tend to be less risk-averse. Their measure of risk attitudes, however, only captures risk-averse up to riskneutral behavior and does not cover the domain of risk proclivity.

Our study goes beyond the existing literature in that it tests the role of selfcontrol guided by the theoretical frameworks of Fudenberg and Levine (2006) and Loewenstein and O'Donoghue (2005). Additionally, we provide particularly clean evidence regarding the effect of ego depletion on risk attitudes. For this purpose, several aspects of the design of our experiment are crucial. We use (i) incentivized choices, (ii) ego depletion is the only manipulation, and (iii) all probabilities associated with the payoffs are known to subjects. Our risk measure (iv) covers the entire domain of possible risk attitudes and (v) enables us to detect even small effect sizes. (vi) We take restrictions on the magnitude of the involved payoffs, as they follow from the Fudenberg-Levine model, into account. Moreover, we use several survey and behavioral responses of our subjects to provide an independent manipulation check, showing that subjects in the treatment group were more depleted than subjects in the control group.

Finally, our sample size $(N=308)$ yields sufficient statistical power to document relevant effect sizes. The average effect size (Cohen's $d$ ) is $d=0.62$ in the meta-analysis by Hagger et al. (2010) that is based on a total of 83 papers containing 198 independent studies. Carter and McCullough (2014) reevaluate the same ego depletion literature and find evidence for small-study effects. In order not to fall prey to this issue, our study features a comparatively large sample size $(N=308$; this exceeds the sample size of all but one of the 198 studies covered by Hagger et al., 2010). Given our large number of observations, a power analysis shows that each of our choice lists has a power of over $99.9 \%$ for detecting an effect size of $d=0.62$ with a $t$-test at a significance level $\alpha=0.05$. Even a smaller effect size of $d=0.4$ would be detected with at least $92.3 \%$ probability for all choice lists.

The rest of the paper is structured as follows. Section 2 presents the model by Fudenberg et al. (2014) and derives hypotheses for the impact of a self-control manipulation on decision making under risk. Section 3 describes the design and procedural details of our laboratory experiment. Section 4 presents the results. Section 5 discusses our findings and concludes.

\section{Theory and hypotheses}

In the psychology literature, it has been argued that depletion induces an increased propensity to engage in risk-seeking behavior (Freeman and Muraven, 2010). The dual-self model by Fudenberg and Levine $(2006,2011)$ makes the opposite prediction: typically, we should observe more pronounced risk aversion under depletion. Fudenberg et al. (2014) explicitly model self-control as a determinant of choices between lotteries. Thus, their model allows us to derive precise hypotheses on the influence of ego depletion on pairwise lottery choice between two-outcome lotteries (as we use in our experiment). 


\subsection{Overview of the model}

In all variants of the Fudenberg-Levine model, decision making is the outcome of the interaction of a short-run and a long-run self. One might think of the interaction between the two selves as that of a "planner" (the long-run self) and a "doer" (the short-run self), a terminology introduced by Thaler and Shefrin (1981). Both "selves" have the same per-period utility function, which is assumed to be monotonically increasing and concave. They differ, however, in the way they regard the future. The short-run self is completely myopic, i.e., it cares only about same-period consumption. ${ }^{5}$ Consequently, it prefers to spend all available income immediately. Having a concave per-period utility function, the short-run self is risk-averse. The long-run self, in contrast, also derives utility from consumption in future periods and discounts them exponentially. Combined with its concave per-period utility function, this creates a preference for smoothing consumption over time. As a consequence of spreading consumption over a large number of periods, the long-run self is (very close to) risk-neutral (for a formal derivation, see Fudenberg and Levine, 2011, p. 44).

The short-run self's preference for immediate consumption and the long-run self's consumption-smoothing motive generate a conflict of interest. By exerting self-control, the long-run self can restrict the short-run self to a consumption level below the latter's desired consumption level. ${ }^{6}$ Exertion of self-control is assumed to be costly. This cost increases in the difference between the short-run self's utility derived from the consumption that the long-run self "allows" and the short-run self's preferred course of action, i.e., spending the entire period income immediately. To fit "the psychological evidence that self-control is a limited resource" as well as to explain the Allais paradox, the self-control cost function has to be convex, as Fudenberg and Levine (2006, p. 1467; 2011; 2012, pp. 3, 16) argue.

In order to improve its applicability, Fudenberg et al. (2014) approximate the original model. Their main simplifying assumption is linearity of the long-run value function. This means that the marginal utility of saving is constant, such that the long-run self is completely risk-neutral. In Appendix A, we use this approximate version of the dual-self model to formally derive Hypotheses 1, 2, and 3. Below we present the hypotheses and provide some intuition for them.

\subsection{Hypotheses}

Hypothesis 1 Ego depletion leads to greater risk aversion for choices between lotteries if at least one of the lotteries contains a small payoff below and another larger payoff above a cutoff value $\hat{z}$.

\footnotetext{
${ }^{5}$ In Fudenberg and Levine (2012), the authors allow for an only partially myopic short-run self.

${ }^{6}$ In the model by Fudenberg and Levine, the described conflict of interest only arises for unanticipated income. Anticipated income does not create a need to exert self-control: Based on foreseeable income, the long-run self allocates a budget to the short-run self of each period, and the short-run selves spend exactly that budget.
} 
In the notation of Fudenberg et al. (2014), $\hat{z}$ denotes a threshold such that monetary lottery payoffs below $\hat{z}$ are spent completely, while any part of a payoff that exceeds $\hat{z}$ is saved for future consumption. The threshold $\hat{z}$ is endogenously determined by the interplay of the long-run self and the short-run self. It depends on the lottery under consideration, the menu of lotteries as well as the marginal cost of self-control. Therefore, ego depletion-which increases the marginal cost of selfcontrol if the cost function is convex-shifts the balance of power in favor of the risk-averse short-run self, resulting in an increase in the degree of risk aversion expressed by the lottery choice. This is due to two effects: First, for a given $\hat{z}$ and a lottery with one payoff below and one payoff above $\hat{z}$, the relative contributions of the short-run self's and the long-run self's utility to the expected utility of this lottery change, with the effect that the combined preferences exhibit increased risk aversion (see Appendix A). Second, the threshold $\hat{z}$ increases. As a consequence, there are decisions which the short-run self is entirely in charge of under depletion even though the long-run self would have exerted self-control under non-depletion.

Hypothesis 2 The effect of ego depletion (i.e., increased risk aversion) is stronger when one "lottery" is a sure payoff.

When the per-period utility function is concave, a sure payoff leads to higher utility than a lottery with the same expected value. Consequently, self-control costs are higher in case the long-run self actually exerts control over the short-run self. Compared to a decision among two two-outcome lotteries, this amplifies the increase in risk aversion due to ego depletion. ${ }^{7}$

Hypothesis 3 When payoffs are delayed, ego depletion has no effect.

In case we observe the effects of ego depletion that we predict in Hypotheses 1 and 2, these need not necessarily be caused by a decrease in self-control resources. Other channels-for instance, a change in the propensity to rely on heuristicscould generate the same effects. Our third hypothesis thus serves to distinguish an influence of self-control from other possible explanations.

For this purpose, we exploit a particular feature of the dual-self model, namely that the short-run self cares only about the current period. Although Fudenberg and Levine (2006) do not specify the length of one period-i.e., the time horizon for one short-run self-it should not exceed a few days. ${ }^{8}$ Thus, when both lotteries exclusively feature payoffs that occur in the future-i.e., beyond the short-run self's time horizon - self-control does not affect decisions. Therefore, self-control costs or an increase in self-control costs will not make a difference for risk attitudes over future payoffs. ${ }^{9}$ If, however, ego depletion affected risk attitudes through

\footnotetext{
${ }^{7}$ See also Fudenberg and Levine (2011, pp. 35, 46, 66).

8 "[T]he horizon of the short-run self is on the order of a day to a week" (Fudenberg and Levine, 2011, p. 39).

${ }^{9}$ See also Fudenberg and Levine (2011, p. 48) for the implication that Allais-type paradoxes disappear "if the results of gambles are delayed long-enough that they fall outside the time horizon of the short-run self."
} 
the increased use of heuristics, this would also be the case for choices concerning the future. Thus, according to this alternative hypothesis, we would find the same change in risk aversion when payoffs are delayed as when they are immediate.

Hypothesis 4 For a long shot, ego depletion leads to a lower degree of risk aversion.

A long shot is a lottery that offers a low probability of obtaining a high payoff and a high probability of obtaining a low payoff. ${ }^{10}$ Hypothesis 4 is based on the idea that the decision maker overweights small probabilities and that this distortion becomes more pronounced under ego depletion. Overweighting the small probability of winning a large amount makes a long shot subjectively attractive despite its being relatively risky. A stronger distortion of the small probability in the direction of $1 / 2$ under ego depletion should thus make risk-averse decision makers less risk-averse, and risk-seeking decision makers more risk-seeking.

Hypothesis 4 is a direct implication of Loewenstein and O'Donoghue (2005, p. 28). It deviates from the Fudenberg-Levine model in that Fudenberg and Levine assume the absence of probability weighting and a strictly risk-averse short-run self. The background of this hypothesis is empirical evidence that many subjects exhibit risk proclivity for long shots (Harbaugh et al., 2010). A common explanation for this phenomenon is probability weighting, in particular overweighting of small probabilities that are associated with large payoffs (as modeled by cumulative prospect theory, Tversky and Kahneman, 1992). Probability weighting is modeled explicitly as the outcome of the interaction of a deliberative and an affective system by both Loewenstein and O'Donoghue (2005) and Mukherjee (2010). In both models, the preferences of the deliberative system can be represented by expected-utility maximization, i.e., the deliberative system takes probabilities at face value. In contrast, the affective system assigns identical weight to all possible outcomes (i.e., $1 / 2$ in the case of two-outcome lotteries) instead of using the associated probabilities. The interplay of both systems then results in an inverse-Sshaped probability weighting function. Loewenstein and O'Donoghue (2005, p. 28) explicitly state that "if a person's willpower is depleted ..., then she should exhibit a more [inverse-]S-shaped probability weighting function”. Thus, for long shots, we expect reduced risk aversion or increased risk proclivity, respectively, under depletion, because attaching a higher probability weight to the large payoff makes picking the long shot more attractive. ${ }^{11}$

\footnotetext{
${ }^{10}$ Long shots are sometimes also referred to as "\$-bets".

${ }^{11}$ The same prediction would follow from the model by Mukherjee (2010) if one assumed that the strength $(\gamma)$ of the affective system relative to the deliberative system in his model depended on selfcontrol resources.
} 


\section{Experiment}

\subsection{General setup}

Our objective is to test whether there is a causal effect of the current level of selfcontrol on risk attitudes. We employ a between-subject design with two treatments in which we exogenously vary the level of self-control using an ego depletion task. ${ }^{12}$ More specifically, subjects in the depletion and in the control treatment work on different versions of a task that bring about different levels of self-control capacity. Subsequently, we measure subjects' risk attitudes via incentivized choices between lotteries.

\subsection{Depletion task}

In our experiment, the depletion task serves as the source of exogenous variation between the two treatments. Being such a vital part of the experiment, we required it to be both well established and as effective as possible in inducing low self-control. The task of our choice, the crossing-out letters task, meets both criteria and is also easily implementable in the lab. According to the meta-analysis of Hagger et al. (2010) the crossing-out letters task is the most effective of all ego depletion tasks. It has been used successfully to induce changes in outcomes like persistence in watching a boring movie, resistance to persuasion, advice on risk taking given to others in a vignette-style questionnaire, and offers made in a dictator game (Baumeister et al., 1998; Wheeler et al., 2007; Freeman and Muraven, 2010; Achtziger et al., 2015, respectively).

In the depletion treatment, the task works as follows. Subjects are first given a printed text spanning 22 rows and are asked to cross out all instances of the letter "e" (including the uppercase letter "E"). ${ }^{13}$ Subjects work on this task for three minutes. Immediately afterwards, they are given a different text spanning 44 rows. This time they are asked to cross out all instances of the letter "e" except when there is a vowel right after the "e" or two letters away (in either direction). Subjects work on this second part of the task for seven minutes. The rationale why this task depletes self-control is that it requires the constant cognitive suppression of an automatic impulse - the impulse to cross out the letter "e" that was built up in the first part of the task.

The control treatment also follows the standard of the literature. Here, subjects work on the same texts for the same time intervals but are only required to cross

\footnotetext{
${ }^{12}$ A within-subject design would have had the advantage of providing us with a baseline measure of risk attitudes at the individual instead of group level. However, we would have needed to present subjects the same lottery choices before and after the self-control manipulation. This would have been a severe drawback because subjects are likely to remember their earlier choices. Paired with a preference for consistency (Falk and Zimmermann, 2014), recalling previous choices might counteract any depletion effect.

${ }^{13}$ We chose a text that we expected to be irrelevant and uninteresting to most subjects. It was taken from the appendix of a statistics text book and described criteria for the choice of statistics software in a very general way.
} 
out all "e"s in both parts. Hence, there is no self-control-consuming impulse suppression in the control treatment.

We deliberately chose not to pay subjects for this task because there is evidence that receiving payment for a task counteracts ego depletion (Muraven and Slessareva, 2003). In addition to announcing and providing private feedback on performance at the end of the experiment, the instructions asked subjects to work on the task conscientiously. The data show that the vast majority of subjects did. ${ }^{14}$

\subsection{Measure of risk attitudes}

We used the following criteria to choose the method for quantifying subjects' risk attitudes:

- It does not require to assume a specific utility function or choice model. ${ }^{15}$

- Lotteries of various types, including long shots (lotteries with a low probability of winning a high prize) and safe choices (degenerate lotteries), need to be implementable.

- It has to allow for the measurement of risk aversion, risk neutrality, and risk proclivity-ideally in a single decision situation.

- It should provide a sufficiently fine measure of risk attitudes to enable us to detect small effect sizes.

Following these criteria, we chose a measure using two-outcome lotteries and mean-preserving spreads of these lotteries. Our method was inspired by Ebert and Wiesen $(2011,2014)$ whose experimental measures are based on the model-independent concept of risk apportionment (Eeckhoudt and Schlesinger, 2006). Ebert and Wiesen (2014) classify an individual as risk-averse if she prefers a lottery $L=\left(c_{L, 1}, p_{L, 1} ; c_{L, 2}, p_{L, 2}\right)=(x-r, 50 \% ; x-k, 50 \%)$ over the lottery $M=$ $\left(c_{M, 1}, p_{M, 1} ; c_{M, 2}, p_{M, 2}\right)=(x-r-k, 50 \% ; x, 50 \%)$, where $x, r$, and $k$ are monetary payoffs. ${ }^{16}$ Note that this coincides with preferring a lottery to a mean-preserving spread of that lottery. In case the individual prefers $M$ over $L$, she is classified as risk-seeking.

To measure the intensity of a subject's risk attitude, we determine the monetary amount $m$ (compensation or "risk premium") that is needed to make her indifferent between the lotteries $L$ and $M+m$. To this purpose, we use a choice list format,

\footnotetext{
${ }^{14}$ For the first paragraph of the first part of the task (which was the same for both treatments) $85 \%$ of subjects reported the correct value or a value within the $10 \%$ interval around the correct value (typically below the correct value).

${ }^{15}$ Please note that we did not design our experiment to enable us to estimate the model's parameters, since this would require simultaneous estimation of utility function $u$ as well as self-control gain function $h$. This is very difficult to achieve due to several unobservable quantities, and it would have to rely on rather strong assumptions.

${ }^{16}$ In general, i.e., with arbitrary probabilities $p_{L, 1}, p_{L, 2}$, Lottery $M$ is constructed by setting $c_{M, 1}=$ $x-\left(p_{L, 2} / p_{L, 1}\right) r-k$. This is needed for constructing the mean-preserving spread of the long shot.
} 
Table 1. Overview of the choice lists presented to subjects.

\begin{tabular}{|c|c|c|c|c|c|c|c|c|}
\hline & \multicolumn{4}{|c|}{ Alternative $A$} & \multicolumn{4}{|c|}{ Alternative $B$} \\
\hline & $C_{A, 1}$ & $p_{A, 1}$ & $c_{A, 2}$ & $p_{A, 2}$ & $C_{B, 1}$ & $p_{B, 1}$ & $C_{B, 2}$ & $p_{B, 2}$ \\
\hline \multicolumn{9}{|c|}{ Choice List A: Risky/Risky ( $x=€ 22.00, r=€ 7.50, k=€ 11.50 ; 25$ rows) } \\
\hline Top row & $€ 3.00$ & $50 \%$ & $€ 22.00$ & $50 \%$ & $€ 3.00$ & $50 \%$ & $€ 7.00$ & $50 \%$ \\
\hline Center row & $€ 3.00$ & $50 \%$ & $€ 22.00$ & $50 \%$ & $€ 9.00$ & $50 \%$ & $€ 13.00$ & $50 \%$ \\
\hline Row with $m=0$ & $€ 3.00$ & $50 \%$ & $€ 22.00$ & $50 \%$ & $€ 10.50$ & $50 \%$ & $€ 14.50$ & $50 \%$ \\
\hline Bottom row & $€ 3.00$ & $50 \%$ & $€ 22.00$ & $50 \%$ & $€ 15.00$ & $50 \%$ & $€ 19.00$ & $50 \%$ \\
\hline \multicolumn{9}{|c|}{ Choice List B: Safe/Risky $(x=€ 16.00, r=€ 5.00, k=€ 5.00 ; 19$ rows) } \\
\hline Top row & $€ 11.00$ & $100 \%$ & & & $€ 11.00$ & $50 \%$ & $€ 21.00$ & $50 \%$ \\
\hline Center row & $€ 11.00$ & $100 \%$ & & & $€ 6.50$ & $50 \%$ & $€ 16.50$ & $50 \%$ \\
\hline Row with $m=0$ & $€ 11.00$ & $100 \%$ & & & $€ 6.00$ & $50 \%$ & $€ 16.00$ & $50 \%$ \\
\hline Bottom row & $€ 11.00$ & $100 \%$ & & & $€ 2.00$ & $50 \%$ & $€ 12.00$ & $50 \%$ \\
\hline \multicolumn{9}{|c|}{ Choice List C: "Long Shot" $(x=€ 14.00, r=-€ 36.00, k=€ 7.00 ; 21$ rows $)$} \\
\hline Top row & $€ 7.00$ & $90 \%$ & $€ 50.00$ & $10 \%$ & $€ 7.00$ & $90 \%$ & $€ 10.00$ & $10 \%$ \\
\hline Row with $m=0$ & $€ 7.00$ & $90 \%$ & $€ 50.00$ & $10 \%$ & $€ 11.00$ & $90 \%$ & $€ 14.00$ & $10 \%$ \\
\hline Center row & $€ 7.00$ & $90 \%$ & $€ 50.00$ & $10 \%$ & $€ 12.00$ & $90 \%$ & $€ 15.00$ & $10 \%$ \\
\hline Bottom row & $€ 7.00$ & $90 \%$ & $€ 50.00$ & $10 \%$ & $€ 17.00$ & $90 \%$ & $€ 20.00$ & $10 \%$ \\
\hline \multicolumn{9}{|c|}{ Choice List D: Delayed Payoffs ( $x=€ 18.00, r=€ 6.00, k=€ 8.50$, paid in one week; 20 rows) } \\
\hline Top row & $€ 9.50$ & $50 \%$ & $€ 12.00$ & $50 \%$ & $€ 9.50$ & $50 \%$ & $€ 24.00$ & $50 \%$ \\
\hline Above-center row & $€ 9.50$ & $50 \%$ & $€ 12.00$ & $50 \%$ & $€ 5.00$ & $50 \%$ & $€ 19.50$ & $50 \%$ \\
\hline Below-center row & $€ 9.50$ & $50 \%$ & $€ 12.00$ & $50 \%$ & $€ 4.50$ & $50 \%$ & $€ 19.00$ & $50 \%$ \\
\hline Row with $m=0$ & $€ 9.50$ & $50 \%$ & $€ 12.00$ & $50 \%$ & $€ 3.50$ & $50 \%$ & $€ 18.00$ & $50 \%$ \\
\hline Bottom row & $€ 9.50$ & $50 \%$ & $€ 12.00$ & $50 \%$ & $€ 0.00$ & $50 \%$ & $€ 14.50$ & $50 \%$ \\
\hline
\end{tabular}

as introduced by Holt and Laury (2002). The switching row in the choice list delivers a proxy of the indifference-generating risk premium $m_{\sim}(L, M)$. If $m_{\sim}(L, M)>0$, the decision maker exhibits risk aversion for that particular lottery pair; conversely, $m_{\sim}(L, M)<0$ indicates risk proclivity.

Table 1 provides an overview of all four choice lists (one per hypothesis) that we used, in the order in which they were presented to subjects. ${ }^{17}$ In the instructions we referred to the choice lists as "tables". A sample screenshot displaying the exact representation that subjects saw is included in Appendix B.

Each choice list starts from a first-order stochastically dominated choice and spans risk aversion, risk neutrality, and risk proclivity. To make the decisions easy for subjects to grasp, probabilities remain the same within a given choice list. Moreover, in all choice lists, the left lottery stays constant, while the right lottery's payoff changes in steps of $€ 0.50$ per row. Additionally, the expected value of "Alternative $A$ " is similar (between $€ 10.75$ and $€ 12.50$ ) for all four choice lists.

\footnotetext{
${ }^{17}$ Choice List A is designed to address Hypothesis 1, while Choice List B relates to Hypothesis 2, Choice List C to Hypothesis 4, and Choice List D to Hypothesis 3.
} 
To address a recent criticism of choice-list-based measurement of risk attitudes by Andersson et al. (2013), we put the expected median switching row in the control condition to the center of each list. ${ }^{18}$

Moreover, we balanced the exposition of our choice lists: in two of our choice lists, the dominated choice in the first row is on the left, and in the other two, it is on the right.

Obviously, there is a trade-off between the brevity of a choice list and the fineness and extent of measurement. Some experimenters solve this by using differently sized increments, i.e., smaller increments in intervals they expect to be most relevant. Since we were concerned that this might confound subjects' choices by steering the switching row in a certain direction, we used constant increments (of €..50) throughout all choice lists. To be able to pick up finer depletion-induced changes in risk attitudes, switching points in four additional "small" choice lists were elicited after subjects had made their choices in all four "large" choice lists. These "small" choice lists consisted of six rows covering the switching range in the respective "large" choice lists and had increments of €o.10.

A particular feature of our computerized implementation of the choice lists is that, once a subject switches, all subsequent rows are automatically filled in. ${ }^{19}$ This was done to let as little time as possible pass between the depletion task and the measurement of risk attitudes. ${ }^{20}$

A final aspect to consider is the value of $\hat{z}$, the theoretical threshold above which all additional income is spent. At least one of the lotteries needs to be such that one outcome is above and one below $\hat{z}$. As the "true" $\hat{z}$ is unobservable, we use two vignettes in the post-experiment questionnaire to gather some information about subjects' individual $\hat{z} .{ }^{21}$ Median values of $\hat{z}$ in the two vignettes are $€_{15}$ and $€_{20}$, respectively. Thus, our design of the choice lists ensures that, for most of the subjects, the vast majority of lottery choices under consideration should be affected by self-control depletion.

\footnotetext{
${ }^{18}$ Andersson et al. (2013) show that when subjects make mistakes that lead to random choice and their "real" risk attitude does not imply a switching row at the center of a choice list, a systematic measurement error towards indifference at the center of the choice list occurs. Thus, we designed our choice lists in such a way that the switching row for the median risk attitude that we expected in the control condition was at the center of the respective choice list. It turns out that our expectations were rather accurate. The median switching row in the control treatment was close to the center (one to three rows above the center) for all choice lists.

${ }^{19}$ Subjects could still adjust their choices and had to press a "Continue" button to confirm their choices before moving on to the next choice list.

${ }^{20}$ While it is typically assumed that self-control resources replenish after some time, we are not aware of any evidence on how long depletion effects last. Furthermore, we did not want to exhaust or annoy subjects, and thus possibly weaken data quality, by forcing them to make 85 clicks.

${ }^{21}$ The vignettes asks subjects to imagine two scenarios. The first is going out with friends in the evening. It asks subjects for the minimal amount of money spent such that they would consider the evening "expensive". The second scenario is passing an item they would like to buy in a store. It asks subjects to state the minimal price of that item that would induce them to deliberate about the expenditure instead of buying the item immediately.
} 


\subsection{Manipulation checks}

We include several manipulation checks in our experiment to be able to assess independently from possible treatment effects whether the depletion task did indeed induce variations in self-control. ${ }^{22}$ Ideally, one would assess subjects' state of selfcontrol at the same time as measuring their risk attitudes. This is, of course, not feasible. One possibility would be to introduce a manipulation check in between the depletion task and the measurement of risk attitudes. Most candidates for manipulation checks (e.g., the Stroop test) are, however, likely to alter subjects' level of self-control themselves. We therefore include a short ad hoc manipulation check that we do not consider depleting right after the depletion task and a more comprehensive, but possibly depleting manipulation check right after measuring risk attitudes. Because self-control resources are generally thought to replenish over time, doing a manipulation check only after the main part of the experiment may have the disadvantage that self-control resources could have already replenished partly or completely.

Our first short ad hoc manipulation check consists of choosing the difficulty of a puzzle (on a scale from one to ten). Our conjecture was that depleted subjects would select an easier puzzle. Since the puzzle is solved only later, the mere choice of the its difficulty level should not affect subjects' level of self-control resources.

The second manipulation check, performed after risk attitudes have been measured, is a computerized version of the Stroop test (Stroop, 1935; MacLeod, 1991). The Stroop test is well-established both as a depletion task and as a dependent variable in depletion studies (see Hagger et al., 2010). In our computerized version, the name of a color appears in bold letters at the center of the screen. The letters themselves are also printed in color. In "congruent trials", this color corresponds to the word's meaning, while it differs from the word's meaning in "incongruent trials." Subjects' task is to indicate the color in which the letters are printed-and not the meaning of the color word. To this end, the screen shows six buttons that are labeled with color names and located on a circle around the bold color word. For a screenshot, see Figure 1. Subjects have to click the button corresponding to the color in which the word is printed as fast as they can. Just as in the depletion task, in incongruent trials of the Stroop test, subjects have exert self-control to suppress an automatic impulse, namely clicking the button corresponding to the meaning of the word. Immediately after each button click, a new word appears. Subjects receive no feedback. In our experiment, subjects work on this task for three minutes. Widely used measures to check for depletion effects are average response times per

\footnotetext{
${ }^{22}$ Most studies using ego depletion do not include independent manipulation checks but simply rely on the effectiveness of the implemented depletion task based on the results of previous studies. We consider the use of independent manipulation checks particularly important in light of the current debate in psychology regarding the presence of small-study effects and publication bias in the ego depletion literature (Carter and McCullough, 2014; Hagger and Chatzisarantis, 2014; Carter et al., 2015).
} 


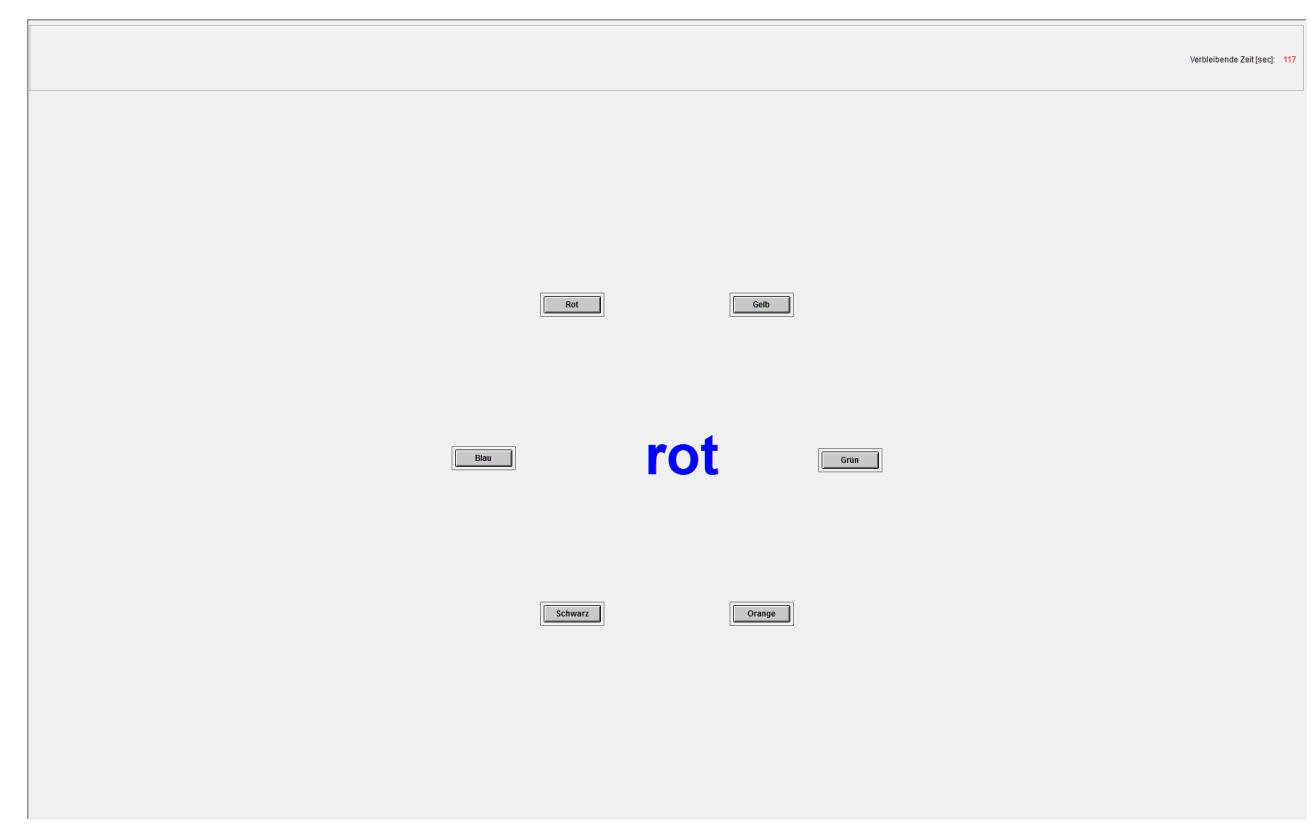

Figure 1. Screenshot of the computerized Stroop (1935) test. The screenshot depicts an incongruent trial, i.e., the meaning of the color word "rot" ("red") does not correspond to the color of the word (blue). Subjects would have to press the "Blau" ("Blue") button.

trial and the share of correct answers. We expect longer response times and a lower share of correct answers in the depletion compared to the control treatment.

As a third manipulation check that has also been employed in several other studies (see Hagger et al., 2010), we asked subjects at the beginning of the final questionnaire how much they had to concentrate in each part of the depletion task and how exhausted they felt before the experiment and at the present moment. For both we calculate differences and compare them across treatments.

Based on these five independent measures of depletion effects (choice of difficulty of a puzzle, response times and share of correct responses in the Stroop test, difference in self-reported need to concentrate during the two parts of depletion task, and difference in self-reported fatigue at beginning and end of the experiment) that all have their distinct strengths and weaknesses, we construct a joint index of depletion by $z$-standardizing each of the five depletion checks, averaging over them, and again $z$-standardizing the result.

\subsection{Procedural details and implementation}

The detailed sequence of events in each session was as follows:

1. Instructions. Upon entering the lab, subjects drew a card containing a number and were asked to sit in the respective booth. They read the instructions, were encouraged to ask questions in private, and answered several control questions on the computer. (A translation of the instructions to English can be found in Appendix C.) 
2. Depletion task. Subjects participated in the treatment-specific version of the crossing-out letters task that either induced low self-control or left self-control unchanged.

3. Manipulation Check 1 . Subjects chose the difficulty of a puzzle (on a scale from 1 to 10$)$ that they solved at the end of the experiment.

4. Measurement of risk attitudes. Subjects made lottery decisions in the four choice lists.

5. Manipulation Check 2. Stroop test.

6. Puzzle. Subjects solved the puzzle with the chosen level of difficulty.

7. Questionnaire, ${ }^{23}$ including Manipulation Check 3 (self-reported required concentration during each part of the depletion task and self-reported exhaustion before and after the experiment).

The experiment was conducted at the BonnEconLab. 308 subjects (152 in the depletion and 156 in the control treatment) participated, each in only one treatment. Most subjects ( $92 \%$ ) were students and majored in various subjects. Age varied between 17 and 55 years (median age, 24; 93\% in the range 19-30 years). ${ }^{24} \mathrm{We}$ used the software z-Tree (Fischbacher, 2007) for conducting the experiment and ORSEE (Greiner, 2004) for inviting subjects from the BonnEconLab's subject pool and recording their participation. The experiment took place in thirteen sessions in July and October 2014. Treatments were balanced with respect to day of the week and time of the day. ${ }^{25}$

In total, the experiment lasted about 75 minutes (including payment). Subjects received the outcome of one randomly drawn lottery decision ( $€ 12.25$ on average) plus an additional $€_{1}$ for filling out the questionnaire. Payments were made in a separate room to ensure privacy. Those subjects for whom the delayed lottery was drawn did not receive the lottery's payoff until a week later. They could choose between a dated bank transfer and collecting the amount in cash in person.

\footnotetext{
${ }^{23}$ The post-experiment questionnaire measured socio-economic and demographic characteristics and assessed subjects' general attitudes towards risk and time, using questions from the SOEP questionnaire (German Socio-Economic Panel). Additionally, ten questions adapted those from Hauge et al. (2014) aimed at measuring which system (the deliberative or the affective one) was involved in the decision-making process of the lottery choice. Subjects also answered a questionnaire on character trait self-control (Tangney et al., 2004; Bertrams and Dickhäuser, 2009) as well as one on negative/ positive affect in the present moment (Watson and Clark, 1999).

${ }^{24}$ Underage subjects have to provide written consent by their parents in order to participate in experiments at the BonnEconLab.

${ }^{25}$ There is empirical work that suggests that both self-control and measured risk attitudes may exhibit a correlation with the time of the day (Kouchaki and Smith, 2014).
} 


\section{Results}

\subsection{Manipulation checks}

Our manipulation checks indicate that subjects in the treatment group were significantly more depleted than their counterparts in the control group (two-sided $t$-test using the aggregate depletion index, $p<0.001$ ). We find Cohen's $d=0.74$, which is comparable to the average effect size of $d^{+}=0.77$ for the "crossing out letters" task reported in the meta-analysis by Hagger et al. (2010).

\subsection{Descriptive statistics}

The switching row in each of the four choice lists measures an individual's risk attitude. More precisely, differences in expected values of the less risky lottery and its mean-preserving spread at the switching row measure an individual's "risk premium" $m_{\sim}$ that has to be added to the riskier lottery to make that subject indifferent between the two lotteries. We calculate this risk premium as the average difference of the expected values in the two rows around the switching point; i.e., a subject who chooses the more risky lottery when the difference in expected values is $€ 2.60$ but switches to the less risky lottery when it is $€ 2.50$ is assigned a risk premium $m_{\sim}=€ 2.55$.

Based on these indifference-generating risk premia, we classify subjects' behavior into four categories: risk-seeking, risk-neutral, risk-averse, and irrational. The behavior of subjects whose risk premium is positive is classified as risk-averse, while a risk premium of zero implies risk neutrality, and a negative risk premium risk proclivity. ${ }^{26} \mathrm{~A}$ low percentage of subjects chose the dominated lottery in the first row. Those choices were classified as irrational and excluded from further analysis, since they do not fit any economic model of preferences over money. ${ }^{27}$

Table 2 displays the absolute and relative frequencies of choices in the choice lists. As expected, for Choice Lists A, B, and D, large percentages (80\% to $89 \%$ ) of subjects made risk-averse choices. For Choice List $\mathrm{C}$, where one of the alternatives is a long shot, i.e., offers a low probability of winning a large prize, only $46 \%$ of subjects are classified as risk-averse. This shift in expressed risk attitudes due to the presence of a long shot is expected, based on the commonly observed fourfold pattern of risk attitudes (Harbaugh et al., 2010) which is usually attributed to an overweighting of the small probability associated with the large payoff.

In addition, the size of the indifference-generating risk premia reacts to differences between the choice lists in a plausible manner: On average, subjects exhibit the highest risk premium ( $\left.m_{\sim}^{\mathrm{A}}=€ 2.69\right)$ for Choice List A (risky vs. risky lottery), i.e.,

\footnotetext{
${ }^{26}$ As we observe switching points instead of points of indifference, we cannot technically observe risk neutrality. We, thus, classify subjects as risk-neutral who switch at or immediately after the riskneutral row $\left(m_{\sim}=0.05\right.$ or $\left.m_{\sim}=-0.05\right)$. Subjects with $m_{\sim}>0.05$ are classified as risk-averse and subjects with $m_{\sim}<-0.05$ as risk-seeking.

${ }^{27}$ We do not exclude these subjects altogether but just their choices for specific lotteries. Our results are robust to excluding those subjects altogether.
} 
Table 2. Categorization of behavior.

\begin{tabular}{|c|c|c|c|c|c|c|}
\hline & \multicolumn{2}{|c|}{ Depletion } & \multicolumn{2}{|c|}{ Control } & \multicolumn{2}{|c|}{ Combined } \\
\hline & Frequency & $\%$ & Frequency & $\%$ & Frequency & $\%$ \\
\hline \multicolumn{7}{|c|}{ Choice List A: Risky/Risky } \\
\hline Risk-seeking & 11 & 7.2 & 8 & 5.1 & 19 & 6.2 \\
\hline Risk-neutral & 15 & 9.9 & 7 & 4.5 & 22 & 7.1 \\
\hline Risk-averse & 124 & 81.6 & 138 & 88.5 & 262 & 85.1 \\
\hline Irrational & 2 & 1.3 & 3 & 1.9 & 5 & 1.6 \\
\hline \multicolumn{7}{|c|}{ Choice List B: Safe/Risky } \\
\hline Risk-seeking & 10 & 6.6 & 11 & 7.1 & 21 & 6.8 \\
\hline Risk-neutral & 12 & 7.9 & 10 & 6.4 & 22 & 7.1 \\
\hline Risk-averse & 119 & 78.3 & 127 & 81.4 & 246 & 79.9 \\
\hline Irrational & 11 & 7.2 & 8 & 5.1 & 19 & 6.2 \\
\hline \multicolumn{7}{|c|}{ Choice List C: "Long Shot" } \\
\hline Risk-seeking & 70 & 46.1 & 72 & 46.2 & 142 & 46.1 \\
\hline Risk-neutral & 9 & 5.9 & 1 & 0.4 & 10 & 3.3 \\
\hline Risk-averse & 68 & 44.7 & 75 & 48.1 & 143 & 46.4 \\
\hline Irrational & 5 & 3.3 & 8 & 5.1 & 13 & 4.2 \\
\hline \multicolumn{7}{|c|}{ Choice List D: Delayed Payoffs } \\
\hline Risk-seeking & 9 & 5.9 & 4 & 2.6 & 13 & 4.2 \\
\hline Risk-neutral & 9 & 5.9 & 8 & 5.1 & 17 & 5.5 \\
\hline Risk-averse & 133 & 87.5 & 141 & 90.4 & 274 & 89.0 \\
\hline Irrational & 1 & 0.7 & 3 & 1.9 & 4 & 1.3 \\
\hline
\end{tabular}

the choice list with the largest difference between the spreads of the two lotteries. We measure an average risk premium of $m_{\sim}^{\mathrm{B}}=€ 1.59$ for Choice List B (safe vs. risky) and $m_{\sim}^{\mathrm{D}}=€ 2.20$ for Choice List $\mathrm{D}$ (delayed payoff). For the long shot, the average risk premium is $m_{\sim}^{\mathrm{C}}=-€ 0.36$, indicating that on average subjects behave in a slightly risk-seeking manner.

The risk premia measured in the different choice lists exhibit significant and positive pairwise correlation coefficients (see Table 3). Hence, we are confident that our measures of risk attitudes pick up systematic variation in underlying individual risk attitudes. While the correlations of $m_{\sim}^{\mathrm{C}}$ - the risk premium for Choice List $\mathrm{C}$, the choice list that incorporates a long shot - with the other risk premia are smaller than the correlations among the risk premia measured in the "regular" Choice Lists A, B, and D, they are still positive. This implies that it is not predominantly so that those who are most risk-averse for the "regular" lotteries are most risk-seeking for the long shot.

\subsection{Treatment effects}

Figure 2 displays subjects' choices in detail and serves as a graphical representation of our main results. The variable on the horizontal axis is the indifferencegenerating "risk premium" $m_{\sim}$, i.e., the difference in expected values between the 
Table 3. Pairwise Pearson's correlation coefficients between risk premia for different choice lists. $p$-values in parentheses.

\begin{tabular}{lccll}
\hline & $m_{\sim}^{\mathrm{A}}$ & $m_{\sim}^{\mathrm{B}}$ & $m_{\sim}^{\mathrm{C}}$ & $m_{\sim}^{\mathrm{D}}$ \\
\hline$m_{\sim}^{\mathrm{A}}$ & 1 & & & \\
\hline$m_{\sim}^{\mathrm{B}}$ & 0.3830 & 1 & & \\
\hline$m_{\sim}^{\mathrm{C}}$ & $(0.0000)$ & & 1 & \\
\hline$m_{\sim}^{\mathrm{D}}$ & 0.3819 & 0.2654 & & \\
& $(0.0000)$ & $(0.0000)$ & 0.3481 & 1 \\
\hline
\end{tabular}

lotteries in the switching row in euros. Thus, subjects to the right of zero are classified as risk-averse, while those to the left are classified as risk-seeking.

Result 1 (Hypotheses 1 and 2) There is no increase in risk aversion under ego depletion.

We do not observe an increase in risk aversion between treatments for any of the choice lists. For Choice Lists A and B, Wilcoxon rank-sum tests do not reject the null hypothesis of no treatment difference in risk premia (two-sided $p=0.245$ and $p=0.253$, respectively). For both choice lists, subjects are even slightly less riskaverse under depletion. Depleted subjects exhibit lower indifference-generating risk premia in both Choice List A $\left(\Delta_{m_{\sim}^{\mathrm{A}}}=€ 0.30\right)$ and Choice List B $\left(\Delta_{m_{\sim}^{\mathrm{B}}}=€ 0.10\right)$.

Result 2 (Hypothesis 3) When payoffs are delayed, ego depletion does not affect risk attitudes.

Also in Choice List D, where all payoffs are delayed by one week, depleted subjects are slightly less risk-averse than subjects in the control group $\left(\Delta_{m_{\sim}^{\mathrm{D}}}=€ 0.22\right)$. Again, this difference is not statistically significant (Wilcoxon rank-sum test, twosided $p=0.278$ ). This is in line with our initial hypothesis. However, this result would only be evidence in support the model by Fudenberg et al. (2014), had Hypotheses 1 and 2 been confirmed by the data.

Result 3 (Hypothesis 4) For long shots, there is no difference in risk attitudes under ego depletion.

For Choice List C, where one of the lotteries yields an outcome of $€_{50}$ with $10 \%$ probability, we hypothesized (based on Loewenstein and O'Donoghue, 2005, p. 28) that ego depletion induces less risk-averse choices through an increased overweighting of the small probability associated with the large payoff. On average, subjects are mildly risk-seeking in the treatment and control group for Choice List C. We again find that depleted subjects made slightly less risk-averse 

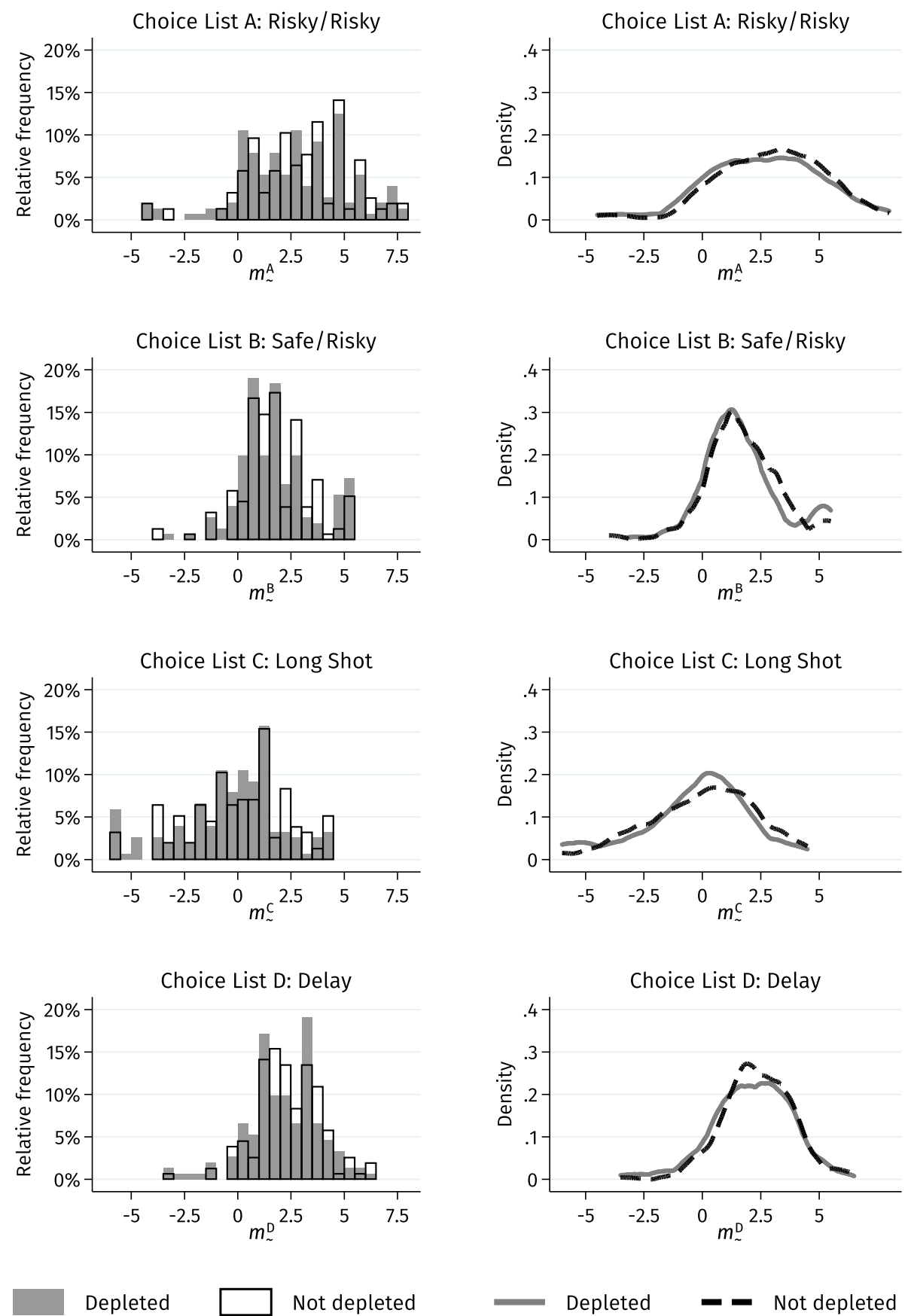

Figure 2. Treatment comparison of indifference-generating risk premia. The horizontal axis displays the indifference-generating risk premia $m_{\sim}$, i.e., the difference in the expected values of the more risky and the less risky lottery at the switching row (in euros). Left column: Histograms of observed risk premia. Right column: Estimated kernel densities (Epanechnikov kernel functions, optimal-bandwidth routine by Stata). 
choices; however, the difference between the two groups is not statistically significant $\left(\Delta_{m_{\sim}^{\mathrm{C}}}=€ 0.28\right.$, Wilcoxon rank-sum test, two-sided $\left.p=0.335\right)$. Thus, we find no evidence in support of the prediction by Loewenstein and O'Donoghue (2005).

Summary. Although our manipulation effectively depleted the self-control resources of subjects in the treatment group, we do not find any significant difference in risk attitudes between subjects in the treatment and control group. However, we observe the same tendency for all four choice lists: ${ }^{28}$ Under depletion, subjects behave in a slightly less risk-averse manner, in contrast to the prediction of the Fudenberg-Levine model.

\section{Discussion and conclusion}

Our goal in this paper is to investigate the causal influence of self-control on risk attitudes. Self-control, a concept from psychology, has been conceptualized and formalized in economics through dual-self models (in particular, Fudenberg and Levine, 2006, 2011, 2012) and dual-system models (in particular, Loewenstein and O'Donoghue, 2005). These models posit that a central determinant of risk attitudes is an individual's current level of self-control.

Using the "approximate dual-self model" by Fudenberg et al. (2014), we derive hypotheses for choices between risky monetary payoffs in a state of low selfcontrol, compared to regular self-control. We show that the model predicts that lower levels of self-control induce stronger risk aversion for stakes within a particular range. We then test the hypotheses in a lab experiment with a large number of subjects by exogenously lowering self-control resources in half of our subjects via so-called ego depletion. We do not find any evidence for increased risk aversion after self-control depletion, contrary to the theoretical predictions. Neither do we find evidence in the opposite direction.

Before discussing the implications of our findings for the modeling of decision making under risk, we exclude several alternative explanations of our data.

A possible concern might be that some of the payoffs of our choice lists were not chosen optimally, i.e., the respective choices did not reflect the case in which, at least in one of the two lotteries, one payoff was below and another above the theoretical cutoff $\hat{z}$. In these cases, the model of Fudenberg et al. (2014) does not predict any effect of ego depletion on risk attitudes. The values of $\hat{z}$ that we measured in the vignettes suggest that this might be the case for about $33 \%$ of the total number of choices (85 per subject), while our payoff choices imply that ego depletion should affect risk attitudes in the remaining $67 \%$ of choices. ${ }^{29}$ We find that our results are robust to excluding those choices for which we predict no effect of ego depletion

\footnotetext{
${ }^{28}$ We create an aggregate measure of behavior over all four choice lists by standardizing the respective risk premia, averaging them, and standardizing again. Also this aggregate measure of risk attitudes reveals that depleted subjects are less risk-averse than control-group subjects but not significantly so (two-sided $t$-test, $p=0.138$ ).

${ }^{29}$ We assign each subject the average $\hat{z}$ from her answers to both vignettes.
} 
on risk attitudes based on the individual $\hat{z}$. In particular, we still do not find any significant difference in risk attitudes between treatment and control group for any of the choice lists (Wilcoxon rank-sum tests, $p=0.487$ for Choice List A, $p=0.915$ for Choice List B, $p=0.326$ for Choice List C, and $p=0.435$ for Choice List D). ${ }^{30}$

A further hypothesis is that self-control depletion has a different effect on risk attitudes than is suggested by the Fudenberg-Levine model. Rather than causing a shift in the distribution of risk preferences, it may make subjects more likely to make mistakes, leading to a higher variance in decisions under depletion. When testing for differences in variances between treatments for a given choice list, we do not find evidence in favor of this hypothesis (Levene's robust test statistic, $W_{0}$, for the equality of variances, $p=0.310$ for Choice List A, $p=0.756$ for Choice List B, $p=0.999$ for Choice List C, and $p=0.069$ for Choice List D).

Alternatively, self-control as a stable character trait might explain heterogeneity in risk attitudes across individuals, ${ }^{31}$ even if temporary changes in self-control as induced by depletion tasks do not have a significant impact on risk preferences. We measure trait self-control in the questionnaire, using the German version of the scale by Tangney et al. (2004) which was translated and validated by Bertrams and Dickhäuser (2009). While trait self-control is, for example, a significant predictor of high school grade point average ("Abiturnote") in our data, it does not explain risk attitudes in any of our choice lists.

Moreover, decision making between treatments might differ in systematic ways which do not manifest themselves in choices. For example, subjects may rely on heuristics to a larger extent in the depletion than in the control treatment (e.g., Loewenstein and O'Donoghue, 2005). It is likely that decision times using heuristics are shorter. We do not find any evidence for this. In fact, decision times in the depletion treatment are slightly longer, albeit insignificantly so ( $t$-test, $p=0.149$ for Choice List A, $p=0.219$ for Choice List B, $p=0.474$ for Choice List C, and $p=0.275$ for Choice List D).

In addition to rejecting these alternative explanations of our data, we have provided evidence on independent manipulation checks that document the effectiveness of our self-control manipulation: subjects in the treatment group were indeed significantly more depleted than those in the control group. Furthermore, our sample size of $N=308$ exceeds the sample size of all but one of the 198 studies on the effects of ego depletion that are covered by the meta-analyses by Hagger et al. (2010) and Carter and McCullough (2014), ${ }^{32}$ and power analyses show that it yields sufficient power to document relevant effect sizes.

Still, we do not find any significant effect of a reduction in self-control resources-induced via ego depletion-on risk attitudes. Contrary to the predic-

\footnotetext{
${ }^{30}$ Subjects are included if the condition that for at least one of the two lotteries one payoff is below and another above their individual average $\hat{z}$ is fulfilled at their individual switching row.

${ }^{31}$ Fudenberg and Levine (2011, p. 57) state, "One possible next step would be to try to more explicitly account for the evident heterogeneity of the population, and estimate distributions of self-control parameters ...."

${ }^{32}$ Actually, only 10 of the 198 studies have a sample size that exceeds 100.
} 
tions that we derive from the model by Fudenberg et al. (2014) with convex selfcontrol costs, there is no evidence for increased risk aversion after ego depletion. Depleted subjects even tend to be less risk-averse, albeit insignificantly so. Due to the careful design of our experiment that was directly inspired by the model of Fudenberg et al. (2014), we consider our results to be powerful null results.

Traditionally, economics has modeled decision makers without any reference to psychological concepts like "self-control". Due to the inability of the standard models of economic choice-expected-utility theory and discounted utility-to explain particular phenomena in intertemporal decision making and decision making under risk, concepts from psychology have been integrated into new models to increase their explanatory power. We have no doubt that economics can benefit from incorporating psychological concepts in general and self-control in particular. For instance, we consider it plausible that self-control plays an important role in savings decisions, addiction, and health-related behavior such as food choice. However, its influence in decision making under risk seems limited: Our results show that different levels of self-control do not carry over to different risk attitudes. Hence, the "unified explanation" offered by Fudenberg and Levine (2006) does not seem to apply, i.e., risk attitudes and intertemporal choice are less interrelated than their model suggests. We also find no evidence for the explanation of probability weighting offered by Loewenstein and O'Donoghue (2005). In this vein, we hope that our empirical results will prove useful in informing future theoretical modeling of decision making under risk.

Despite our findings, we regard developing models inspired by dual-system approaches a beneficial enterprise (see the recent review by Alós-Ferrer and Strack, 2014). Importantly, our findings do not rule out the possibility that decision making under risk is produced by the interaction of multiple systems. They do indicate, however, that the relation between the involved systems is not one in which self-control resources are needed for one system to overwrite the response of the other. ${ }^{33}$ In summary, we consider both research on dual-self models and research on self-control phenomena important ways to extend standard economic theory, but the role of self-control in decision making under risk is most likely limited.

\footnotetext{
${ }^{33}$ This is the very point in which Mukherjee (2010) disagrees with Loewenstein and O'Donoghue (2005): His model of the interaction between the "deliberative" and the "affective" system is formally identical to the one in Loewenstein and O'Donoghue. Still, he demarcates his work from the latter by pointing out that Loewenstein and O'Donoghue assume that the interaction of the two systems depends crucially on "the availability and cost of willpower", while his "treatment of the affective system is geared toward ... subjective feeling states” (p. 252).
} 


\section{Appendix A Derivation of hypotheses from the approximate model by Fudenberg et al. (2014)}

We briefly sketched the Fudenberg-Levine model in Section 2.1. In the following, we describe the interaction between the long-run and the short-run self in greater detail. In particular, we examine pairwise choice between two-outcome lotteries in the approximate model developed by Fudenberg et al. (2014). Finally, we explicitly incorporate self-control depletion in the model so that we can derive hypotheses concerning its effect on choices between two-outcome lotteries.

\section{A.1 The model in detail}

A.1.1 Mental accounting. Just like in Fudenberg and Levine (2006, 2011), agents in the approximate model (Fudenberg et al., 2014) use mental accounting - the mental assignment of expenditures to different accounts-as a means to avoid costly self-control. ${ }^{34}$ An agent in this model lives for several periods. Each of these periods can be thought of as being mentally divided into two subperiods, a "banking period" for planning and a "nightclub period" for spending money. During the banking subperiod, there is no possibility for consumption. Instead, the long-run self plans how much "pocket cash" $x$ to take to the night club and how much to save for future periods. In other words, it chooses an expenditure level for the second subperiod. During the night-club subperiod, the short-run self spends all "pocket cash", and no self-control costs arise.

There can be unanticipated income ("windfall profits") during the night-club period. This income can be stochastic, and it can present itself in the form of multiple income opportunities between which the agent can choose, such that the realized income depends on the agent's choice (e.g., accepting or declining the offer to substitute for a coworker who has called in sick on short notice). Following the notation in Fudenberg et al. (2014), let consumption $c$ refer to consumption on top of the planned consumption level $x$. In such a situation, once planned consumption $x$ has been determined, the short-run self's choice between unanticipated income opportunities depends on $c$ only. Hence, we suppress $x$ in our notation and can denote the short-run self's consumption utility as a function $u(c)$. It is assumed that $u^{\prime}(c)>0$ and $u^{\prime \prime}(c)<0$. Note that, unlike "standard" consumption levels, $c$ can be negative, as long as $c>-x$.

A.1.2 Lotteries. In this setup, unexpectedly facing a set $\Im$ of income opportunities is a situation in which self-control becomes relevant. Lotteries are denoted as discrete random variables $Z \in \Im$ that can take on values $z_{1}, \ldots, z_{n}$, the lotteries' outcomes. Since the short-run self only cares about immediate consumption, its preferred plan of action is to spend all lottery gains immediately and, thus, to choose the lottery with the highest expected short-run utility $\mathrm{E} u(Z)$. The utility derived from this is called "temptation" and denoted $u^{\star}(\Im) \equiv \max _{Z \in \Im} \mathrm{E} u(Z){ }^{35}$ The long-run self, in contrast, prefers to smooth consumption over time. Its value function is therefore close to risk-neutral. Through use of self-control it enforces an action that balances the short-run self's want for immediate consumption and its own preference for consumption smoothing.

\footnotetext{
${ }^{34}$ What is referred to as mental accounting here is only one component of mental accounting as described in Thaler and Shefrin (1981).

${ }^{35}$ For notational convenience, we suppress the dependence of temptation $u^{\star}$ on the menu $\Im$ in the following.
} 
A.1.3 Self-control. This act of self-control is assumed to be costly, with the cost depending on the temptation $u^{\star}$ as well as the actual consumption plan $\tilde{c}$ that the long-run self enforces. This cost enters the overall objective function through a self-control cost function $g\left[u^{\star}-\mathrm{E} u(\tilde{c})\right]$. The function $g[\cdot]$ is assumed to be smooth, nondecreasing, and weakly convex. ${ }^{36}$ Its argument, $u^{\star}-\mathrm{E} u(\tilde{c})$, can be interpreted as foregone utility: (expected) utility that the short-run self was not allowed to realize due to being restricted by the longrun self. If $\mathrm{E} u(\tilde{c})=u^{\star}$, no self-control is exerted and, consequently, no costs arise, $g[0]=0$. Whenever the long-run self enforces an (expected) level of utility that is lower than the one desired by the short-run self, i.e., whenever $\mathrm{E} u(\tilde{c})<u^{\star}$, self-control costs are nonnegative: $g\left[u^{\star}-\mathrm{E} u(\tilde{c})\right] \geq 0$. It is important to note that this makes preferences over lotteries menu-dependent, because these preferences depend on self-control costs which depend on temptation $u^{\star}$ which, in turn, depends on the menu of lotteries $\Im$.

\section{A.2 Optimization}

We will now consider preferences over menus of unanticipated lotteries, which match the situation in the lab. We address the decision problem that an agent faces when picking a lottery $Z$ from menu $\Im$ in two steps. We first calculate optimal consumption for an arbitrary lottery. Then we derive how lotteries are ranked for two-outcome lotteries-the case that we employ in our experiment.

A.2.1 Optimal consumption plan in the presence of self-control costs. For each lottery in the menu $\Im$, the agent chooses a contingent consumption plan $\tilde{c}$ with outcomes $\left(c_{1}, \ldots, c_{n}\right)$, where $c_{i}$ is consumption in case the lottery outcome $z_{i}$ realizes $(i=1, \ldots, n)$. Note that choosing the optimal consumption plan is equivalent to choosing an optimal level of self-control for each of the $n$ lottery outcomes. It is determined by equating the marginal cost from exerting self-control and the marginal gain from saving for future periods.

The first-period utility for each lottery is $\mathrm{E} u(\tilde{c})-g\left[u^{\star}-\mathrm{E} u(\tilde{c})\right]$. Representing all future utility using a value function $v$, the discounted present value of all future consumption is $\delta \mathrm{E} v\left(w_{2}+Z-\tilde{c}\right)$. Here, $w_{2}$ denotes total wealth at the beginning of the next period, $\delta$ is the discount factor, and $Z-\tilde{c}$ is the random savings plan implied by consumption plan $\tilde{c}$.

Thus, we get an overall objective function of

$$
V\left(\tilde{c}, u^{\star}, Z, w_{2}\right)=\underbrace{\mathrm{E} u(\tilde{c})-g\left[u^{\star}-\mathrm{E} u(\tilde{c})\right]}_{1^{\text {st }} \text {-period utility }}+\underbrace{\delta \mathrm{E} v\left(w_{2}+Z-\tilde{c}\right)}_{\text {future utititity }} .
$$

A.2.2 Approximate model. Fudenberg et al. (2014) derive an approximate objective function from this as follows.

First, the authors define a "self-control gain function" $h\left[\mathrm{E} u(\tilde{c})-u^{\star}\right] \equiv$ $\mathrm{E} u(\tilde{c})-u^{\star}-g\left[u^{\star}-\mathrm{E} u(\tilde{c})\right]$ which is substituted into the objective function. It captures the effect of exerting self-control on first-period utility. At $\mathrm{E} u(\tilde{c})=u^{\star}$, no self-control is exerted, and neither a cost nor a benefit arises. Exerting an additional unit of self-control both increases the cost of self-control, $g\left[u^{\star}-\mathrm{E} u(\tilde{c})\right]$, and lowers $\mathrm{E} u(\tilde{c})-u^{\star}$, the expected utility for consumption plan $\tilde{c}$ compared to succumbing to temptation completely, i.e., receiving $u^{\star}$. The function $h[\cdot]$ is nonpositive, smooth, strictly increasing, and weakly

${ }^{36}$ In order to model potential effects of varying levels of self-control, a convex self-control cost function is the relevant-and realistic_case to consider (see Fudenberg and Levine, 2006, Section V). 
concave, while its argument is nonpositive by definition. Furthermore, it holds that $h^{\prime}(0) \geq 1$.

Additionally, the authors perform a first-order Taylor approximation of the unknown value function $v$. It is by virtue of this approximation that the long-run self in the approximate model is completely risk-neutral-instead of only being very close to risk-neutral, as in the original model.

Note that, since the level of pocket cash was chosen optimally in the absence of selfcontrol problems, we know that at $c=0$ (no incremental consumption), it must hold that $u^{\prime}(0)=\delta v^{\prime}\left(w_{2}\right)$. This is a useful observation since the unknown expression $\delta v^{\prime}\left(w_{2}\right)$ can be replaced by $u^{\prime}(0)$.

These two steps lead to the following approximate objective function:

$$
\max _{\tilde{c}} U^{c}\left(\tilde{c}, u^{\star}, Z\right)=\max _{\tilde{c}}\left\{h\left[\mathrm{E} u(\tilde{c})-u^{\star}\right]+u^{\prime}(0)(\mathrm{E} Z-\mathrm{E} \tilde{c})\right\} .
$$

This optimization problem over $\tilde{c}$ is constrained by $c_{i} \leq z_{i}$ for $i=1,2, \ldots, n$.

Fudenberg et al. (2014)'s main theorem (p. 57) states that this optimization problem over the optimal consumption plan (a vector of dimension $n$ ) is equal to an optimization problem where the choice variable is a single threshold, denoted $z$. All lottery earnings are spent in full for realizations below $z$, while above $z$, self-control is exerted, and all earnings beyond $z$ are saved:

$$
\begin{gathered}
\max _{z} U\left(u^{\star}, Z, z\right), \text { where } \\
U\left(u^{\star}, Z, z\right) \equiv h\left[\mathrm{E} u(Z)-u^{\star}-\operatorname{Emax}\{u(Z)-u(z), 0\}\right]+u^{\prime}(0) \operatorname{Emax}\{Z-z, 0\} .
\end{gathered}
$$

The optimal $z$ that solves this problem is denoted

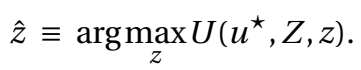

Note that this value is specific to each lottery and menu, as it depends on both $Z$ and the menu-dependent $u^{\star}$. Refer to the main theorem in Fudenberg et al. (2014) for proof.

A.2.3 Ranking two-outcome lotteries. The final step in the agent's optimization problem is choosing between lotteries, taking into account the lottery-specific optimal consumption plans as they were derived above. That is, the agent ranks lotteries $Z$ according to $U\left(u^{\star}, Z, \hat{z}\right)$. While the preceding derivation was general, the following will be specific to the case that we use in our experiment: pairwise choice between two-outcome lotteries. Let us denote these lotteries as discrete random variables $Z^{A}$ (with possible realizations $z_{1}^{A}$ and $z_{2}^{A}$ ) and $Z^{B}$ (with possible realizations $z_{1}^{B}$ and $z_{2}^{B}$ ). Assume $z_{1}^{A} \leq z_{2}^{A}$ and $z_{1}^{B} \leq z_{2}^{B}$, without loss of generality.

In our experiment, we test whether subjects' choices, i.e., their pairwise lottery rankings, change in response to an increase in self-control costs due to ego depletion. Formally, such preference reversals come about when the slope of an agent's indifference curve, $\mathrm{d} z_{2} /\left.\mathrm{d} z_{1}\right|_{U=\text { const }}$ (i.e., her willingness to accept a reduction in one payoff of the lottery in exchange for an increase in the second payoff, holding expected utility constant), changes. Thus, to derive predictions about how an increase in self-control costs affects agents' lottery choices, we need to consider the effect of increased self-control costs on the slope of their indifference curves.

Let us denote by $\hat{z}^{A}$ the optimal cutoff value associated with Lottery $Z^{A}$ and by $\hat{z}^{B}$ the optimal cutoff value associated with Lottery $Z^{B}$, given that the menu is $\Im=\left\{Z^{A}, Z^{B}\right\}$. (Re- 
member that each cutoff value, and thus the ranking of the lotteries, is menu-dependent through $u^{\star}=\max \left\{\mathrm{E} u\left(Z^{A}\right), \mathrm{E} u\left(Z^{B}\right)\right\}$.)

The indifference set for a "reference lottery" $Z^{A}, \mathbb{I}\left(Z^{A} \mid \Im\right)$, is the set of all lotteries $Z^{B}$ for which the agent is indifferent when given the choice between $Z^{A}$ and $Z^{B}$, i.e., $\mathbb{I}\left(Z^{A} \mid \Im\right) \equiv\left\{Z^{B} \mid U\left(u^{\star}, Z^{A}, \hat{z}^{A}\right)=U\left(u^{\star}, Z^{B}, \hat{z}^{B}\right)\right\}$. It is implicitly defined by

$$
\underbrace{U\left(u^{\star}, Z^{A}, \hat{z}^{A}\right)-U\left(u^{\star}, Z^{B}, \hat{z}^{B}\right)}_{\equiv \Phi\left(Z^{A}, Z^{B}, u^{\star}, \hat{z}^{A}, \hat{z}^{B}\right)}=0 .
$$

Note that $\Phi(\cdot)$ is a function of $z_{1}^{B}$ and $z_{2}^{B}$ and the associated probabilities $p$ and $1-p$, respectively-as well as $Z^{A}, u^{\star}, \hat{z}^{A}$, and $\hat{z}^{B}$. To be able to determine the slope of the indifference curve, i.e., $\mathrm{d} z_{2}^{B} / \mathrm{d} z_{1}^{B}$, we use the implicit function theorem. One of its prerequisites is continuous differentiability of the function $\Phi(\cdot)$ with respect to $z_{1}^{B}$ and $z_{2}^{B}$, at least in some neighborhood of the point $Z^{A}=Z^{B}$, which is where we calculate the slope. It can be shown that at this point, $\mathrm{d} \Phi / \mathrm{d} u^{\star}=0$. In addition, it holds for any $Z^{A}, Z^{B}$ that $\mathrm{d} \Phi / \mathrm{d} \hat{z}^{A}=$ $\mathrm{d} \Phi / \mathrm{d} \hat{z}^{B}=0$. This is because $\hat{z}^{A}$ and $\hat{z}^{B}$ maximize $U\left(u^{\star}, Z^{A}, z^{A}\right)$ and $U\left(u^{\star}, Z^{B}, z^{B}\right)$, respectively. Therefore, we only need to consider the dependence of $\Phi(\cdot)$ on $z_{1}^{B}$ and $z_{2}^{B}$ through the direct dependence of $U\left(u^{\star}, Z^{B}, \hat{z}^{B}\right)$ on these values, i.e., the partial derivatives $\partial U\left(u^{\star}, Z^{B}, \hat{z}^{B}\right) / \partial z_{i}^{B}$ with $i=1,2$.

Via the implicit function theorem, it holds that

$$
\begin{aligned}
& \frac{\mathrm{d} \Phi(\cdot)}{\mathrm{d} z_{1}^{B}}+\frac{\mathrm{d} \Phi(\cdot)}{\mathrm{d} z_{2}^{B}} \frac{\mathrm{d} z_{2}^{B}}{\mathrm{~d} z_{1}^{B}}=0 \\
& \Longleftrightarrow \quad \frac{\mathrm{d} z_{2}^{B}}{\mathrm{~d} z_{1}^{B}}=-\frac{\mathrm{d} \Phi(\cdot)}{\mathrm{d} z_{1}^{B}} / \frac{\mathrm{d} \Phi(\cdot)}{\mathrm{d} z_{2}^{B}} \\
& \Longrightarrow \quad \frac{\mathrm{d} z_{2}^{B}}{\mathrm{~d} z_{1}^{B}}=-\frac{\partial U\left(u^{\star}, Z^{B}, \hat{z}^{B}\right)}{\partial z_{1}^{B}} / \frac{\partial U\left(u^{\star}, Z^{B}, \hat{z}^{B}\right)}{\partial z_{2}^{B}} .
\end{aligned}
$$

Recall that the probability of payoff $z_{1}^{B}$ is $p$ and that of $z_{2}^{B}$ is $1-p$. Then

$$
\begin{aligned}
U\left(u^{\star}, Z^{B}, \hat{z}^{B}\right)= & h\left[\mathrm{E} u\left(Z^{B}\right)-u^{\star}-\mathrm{E} \max \left\{u\left(Z^{B}\right)-u\left(\hat{z}^{B}\right), 0\right\}\right]+u^{\prime}(0) \operatorname{Emax}\left\{Z^{B}-\hat{z}^{B}, 0\right\} \\
= & h\left[p u\left(z_{1}^{B}\right)+(1-p) u\left(z_{2}^{B}\right)-u^{\star}-\right. \\
& \left.\quad p \max \left\{u\left(z_{1}^{B}\right)-u\left(\hat{z}^{B}\right), 0\right\}-(1-p) \max \left\{u\left(z_{2}^{B}\right)-u\left(\hat{z}^{B}\right), 0\right\}\right] \\
& +u^{\prime}(0)\left[p \max \left\{z_{1}^{B}-\hat{z}^{B}, 0\right\}+(1-p) \max \left\{z_{2}^{B}-\hat{z}^{B}, 0\right\}\right] .
\end{aligned}
$$

For the derivatives with respect to $z_{1}^{B}$ and $z_{2}^{B}$, we get

$$
\frac{\partial U\left(u^{\star}, Z^{B}, \hat{z}^{B}\right)}{\partial z_{1}^{B}}= \begin{cases}h^{\prime}\left[\mathrm{E} u\left(Z^{B}\right)-u^{\star}-(1-p) \max \left\{u\left(z_{2}^{B}\right)-u\left(\hat{z}^{B}\right), 0\right\}\right] p u^{\prime}\left(z_{1}^{B}\right) & \text { if } z_{1}^{B}<\hat{z}^{B} \\ u^{\prime}(0) p & \text { if } z_{1}^{B}>\hat{z}^{B}\end{cases}
$$

and

$$
\frac{\partial U\left(u^{\star}, Z^{B}, \hat{z}^{B}\right)}{\partial z_{2}^{B}}=\left\{\begin{array}{ll}
h^{\prime}\left[\mathrm{E} u\left(Z^{B}\right)-u^{\star}-p \max \left\{u\left(z_{1}^{B}\right)-u\left(\hat{z}^{B}\right), 0\right\}\right](1-p) u^{\prime}\left(z_{2}^{B}\right) & \text { if } z_{2}^{B}<\hat{z}^{B} \\
u^{\prime}(0)(1-p) & \text { if } z_{2}^{B}>\hat{z}^{B}
\end{array} .\right.
$$

A.2.4 Case distinctions. Since the following reasoning applies to arbitrary two-outcome lotteries $Z$, we now drop the superscript $B$. The dependence of utility on the cutoff $\hat{z}$ im- 
plies that when calculating the slopes of the indifference curves that describe preferences over two-outcome lotteries, we need to distinguish three cases. Remember that temptation $u^{\star}$ is menu-dependent but identical for both lotteries, while the threshold $\hat{z}$ is menudependent (through $u^{\star}$ ) and at the same time lottery-specific. Hence, whenever it holds that $z_{1}<\hat{z}<z_{2}$ (the 3 rd case below) for at least one of the two lotteries, self-control affects the curvature of the indifference curves and, thus, the agent's risk attitudes when she chooses among two lotteries.

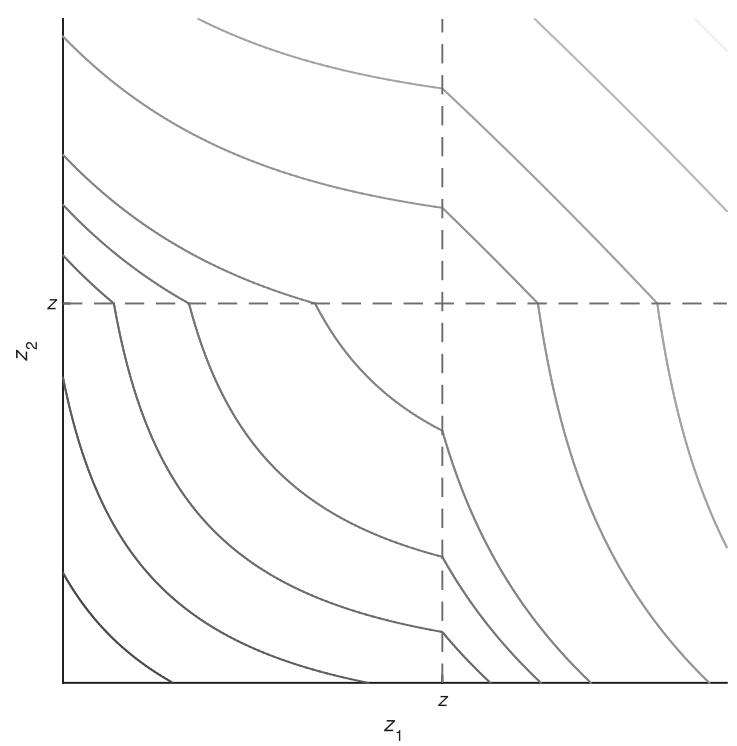

Figure A.1. Illustration of the three cases. Displayed are indifference curves over two-outcome lotteries with payoffs $z_{1}$ and $z_{2}$, associated probabilities $p_{1}=p_{2}=0.5$, and cutoff $z$. The agent's indifference curves are linear for $z_{1}>z$ and $z_{2}>z$ while they are concave elsewhere. For $z_{1}<z$ and $z_{2}<z$ the curvature is strongest. Note that this graph only serves to illustrate the rationale of (A.6), (A.7), and (A.8). The optimal cutoff $\hat{z}$ is lottery-dependent, and $z$ will thus differ depending on which lottery is considered.

$1^{\text {st }}$ case: $\max \left\{z_{1}, z_{2}\right\} \leq \hat{z}$. In this case, the short-run self spends all additional income. Hence, the slope of the indifference curve is

$$
\frac{\mathrm{d} z_{2}}{\mathrm{~d} z_{1}}=-\frac{h^{\prime}\left[\mathrm{E} u(Z)-u^{\star}\right] p u^{\prime}\left(z_{1}\right)}{h^{\prime}\left[\mathrm{E} u(Z)-u^{\star}\right](1-p) u^{\prime}\left(z_{2}\right)}=-\frac{p u^{\prime}\left(z_{1}\right)}{(1-p) u^{\prime}\left(z_{2}\right)} .
$$

Thus, in the $1^{\text {st }}$ case, the combined preferences of the two selves correspond to those of the short-run self, i.e., risk aversion. If all lotteries in the menu fall into this category, they are ranked according to $\mathrm{E} u(Z)$, expected utility with the short-run self's degree of risk aversion.

$2^{\text {nd }}$ case: $\hat{z} \leq \min \left\{z_{1}, z_{2}\right\}$. In this case, the amount that the short-run self is permitted by the long-run self to spend in addition to its initial allowance is smaller than all of the lottery outcomes. Thus, the short-run self derives the same utility from all outcomes, and the agent's combined preferences over lotteries correspond to those of the long- 
run self. Consequently, the slope of the indifference curve is

$$
\frac{\mathrm{d} z_{2}}{\mathrm{~d} z_{1}}=-\frac{p u^{\prime}(0)}{(1-p) u^{\prime}(0)}=-\frac{p}{1-p} .
$$

Thus, if all lotteries in the menu fall into this category, the agent behaves in a riskneutral manner, and lotteries are ranked according to their expected value $\mathrm{E}(Z)$.

$3^{\text {rd }}$ case: $z_{1}<\hat{z}<z_{2}$. In this case, one outcome is below and the other is above the cutoff $\hat{z}$, so that the slope of the indifference curves depends on $h^{\prime}[\cdot]$,

$$
\frac{\mathrm{d} z_{2}}{\mathrm{~d} z_{1}}=-\frac{h^{\prime}\left[p u\left(z_{1}\right)-u^{\star}+(1-p) u(\hat{z})\right] p u^{\prime}\left(z_{1}\right)}{(1-p) u^{\prime}(0)} .
$$

Only in this $3^{\text {rd }}$ case does the slope of the self-control gain function enter the slope of the indifference curves.

Consequently, only in the $3^{\text {rd }}$ case does the slope of the indifference curves change under self-control depletion, such that depletion can lead to changes in lottery choices, i.e., measured risk attitudes.

\section{A.3 Depletion: Model predictions and hypotheses}

A.3.1 Incorporating different levels of self-control. We now apply the model's predictions for two-outcome lotteries to derive specific hypotheses concerning the effects of selfcontrol depletion. We incorporate depletion and the resulting increase in marginal selfcontrol costs into the model by defining different self-control cost functions $g^{\mathrm{ND}}[\cdot]$ and $g^{\mathrm{D}}[\cdot]$ for the nondepleted and the depleted state, respectively.

Recall that a greater $u^{\star}-\mathrm{E} u(\tilde{c})$ denotes a greater amount of exerted self-control. Also recall that $u^{\star}-\mathrm{E} u(\tilde{c}) \geq 0, g\left[u^{\star}-\mathrm{E} u(\tilde{c})\right] \geq 0$, and $g[0]=0$. We assume that

$$
g^{\mathrm{ND}}\left[u^{\star}-\mathrm{E} u(\tilde{c})\right] \leq g^{\mathrm{D}}\left[u^{\star}-\mathrm{E} u(\tilde{c})\right] \text { for all } u^{\star}-\mathrm{E} u(\tilde{c}) \cdot{ }^{37}
$$

The "self-control gain function" was defined as $h\left[\mathrm{E} u(\tilde{c})-u^{\star}\right] \equiv \mathrm{E} u(\tilde{c})-u^{\star}-$ $g\left[u^{\star}-\mathrm{E} u(\tilde{c})\right]$; hence, $h\left[\mathrm{E} u(\tilde{c})-u^{\star}\right] \leq 0$ and $h[0]=0$. Thus, with $h^{\mathrm{ND}}\left[\mathrm{E} u(\tilde{c})-u^{\star}\right] \equiv$ $\mathrm{E} u(\tilde{c})-u^{\star}-g^{\mathrm{ND}}\left[u^{\star}-\mathrm{E} u(\tilde{c})\right]$ and $h^{\mathrm{D}}\left[\mathrm{E} u(\tilde{c})-u^{\star}\right] \equiv \mathrm{E} u(\tilde{c})-u^{\star}-g^{\mathrm{D}}\left[u^{\star}-\mathrm{E} u(\tilde{c})\right]$, we have

$$
h^{\mathrm{ND}}\left[\mathrm{E} u(\tilde{c})-u^{\star}\right] \geq h^{\mathrm{D}}\left[\mathrm{E} u(\tilde{c})-u^{\star}\right] \text { for all } \mathrm{E} u(\tilde{c})-u^{\star} .
$$

The function $g\left[u^{\star}-\mathrm{E} u(\tilde{c})\right]$ was assumed to be weakly convex. Therefore, $g^{\mathrm{ND}}[\cdot] \leq g^{\mathrm{D}}[\cdot]$ implies $g^{\mathrm{ND}^{\prime}}[\cdot] \leq g^{\mathrm{D}^{\prime}}[\cdot]$. It follows that $h\left[\mathrm{E} u(\tilde{c})-u^{\star}\right]$ is weakly concave and that

$$
h^{\mathrm{ND}^{\prime}}\left[\mathrm{E} u(\tilde{c})-u^{\star}\right] \leq h^{\mathrm{D}^{\prime}}\left[\mathrm{E} u(\tilde{c})-u^{\star}\right] \text { for all } \mathrm{E} u(\tilde{c})-u^{\star} .
$$

Intuitively, an increase in the marginal cost of self-control affects optimal choice by increasing the relative importance of the self-control costs in the current period compared to the benefit of saving for future periods. In other words, the short-run self's interest to consume right now becomes more important. This has two effects. The first is immediately apparent from (A.8). When plugging in a higher value for $h^{\prime}[\cdot]$ in (A.8), the slope of

${ }^{37}$ This is conceptually very similar to the way in which Fudenberg and Levine (2006, Section V) incorporate cognitive load in their original model, by adding an amount $d$ to $u^{\star}-\mathrm{E} u(\tilde{c})$. 
the indifference curve becomes steeper. Thus, the agent's combined risk attitudes exhibit more risk aversion. The second effect of an increase in marginal self-control costs is that $\hat{z}$ increases for each lottery. A higher $\hat{z}$ implies that some lotteries will be evaluated by (A.6) that were formerly evaluated by (A.8) and some lotteries will be evaluated by (A.8) that were formerly evaluated by (A.7). Both effects result in increased aversion.

A.3.2 Hypotheses. For one or both of these mechanisms to affect choices, at least one of the two lotteries needs to be such that (A.8) applies in at least one of the states (depletion or nondepletion). This leads us to our first hypothesis:

Hypothesis 1 Ego depletion leads to greater risk aversion for choices between lotteries if at least one of the lotteries contains a small payoff below and another larger payoff above a cutoff value $\hat{z}$.

Our second hypothesis refers to the case in which one of the lotteries is a sure payoff:

Hypothesis 2 The effect of ego depletion (i.e., increased risk aversion) is stronger when one "lottery" is a sure payoff.

If the per-period utility function is concave, a sure payoff leads to higher short-run utility than a lottery with the same expected value. A sure payoff is, thus, more tempting. (See also Fudenberg and Levine, 2011, pp. 35, 46, 66.) With a more tempting reference lottery, the function $g\left[u^{\star}-\mathrm{E} u(\tilde{c})\right]$ is evaluated at a higher level $u^{\star}-\mathrm{E} u(\tilde{c})$ than for a less tempting reference lottery. Consequently, $h\left[\mathrm{E} u(\tilde{c})-u^{\star}\right]$ and $h^{\prime}\left[\mathrm{E} u(\tilde{c})-u^{\star}\right]$ are evaluated for more negative $\mathrm{E} u(\tilde{c})-u^{\star}$. As $h\left[\mathrm{E} u(\tilde{c})-u^{\star}\right]$ is weakly concave, the difference in the slopes of the indifference curves under depletion and nondepletion will be larger with a riskless reference lottery than with a risky reference lottery. Again, this holds only if for at least one of the two lotteries in the menu, one lottery outcome is below and the other is above the cutoff $\hat{z}$.

Our third hypothesis serves to differentiate the dual-self model from other models that potentially make similar predictions as Hypotheses 1 and 2. It does so by outlining a situation in which changes in self-control should show no effect according to the model, while, for instance, increased reliance on heuristics would generate an effect.

Hypothesis 3 When payoffs are delayed, ego depletion has no effect.

The intuition for Hypothesis 3 is provided in the main text. 


\section{Appendix B Example table}

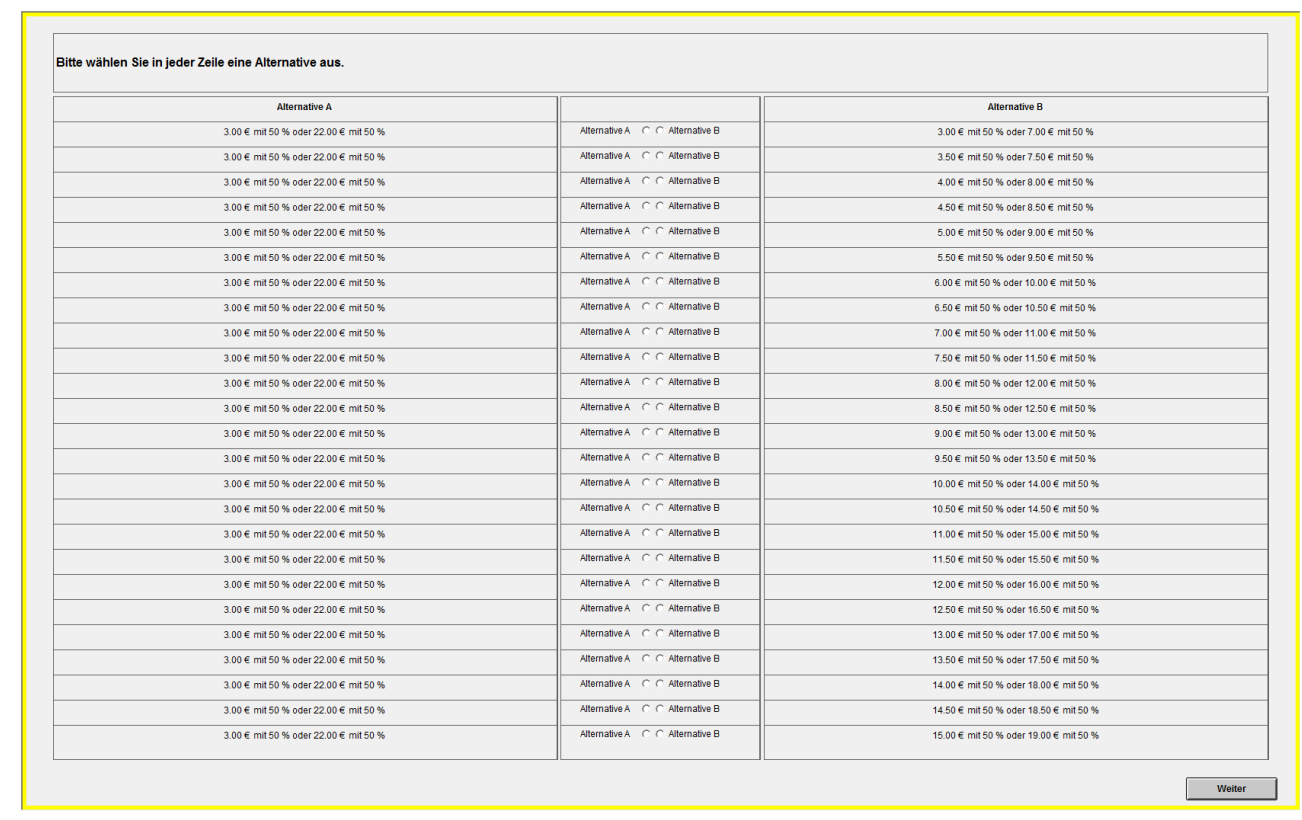

Figure B.1. Choice List (“Table”) A: Risky versus Risky.

Translation: "Please choose one alternative in each row.

Alternative A [first row:] $€ 3.00$ with $50 \%$ or $€ 22.00$ with $50 \%$

Alternative B [first row:] $€ 3.00$ with $50 \%$ or $€ 7.00$ with $50 \% "$.

\section{Appendix C Translated instructions for the depletion [control] treatment}

\section{General Explanations}

Welcome to this economic experiment.

In the course of this experiment you can earn a nonnegligible amount of money. The exact amount strongly depends on your decisions. So please read the following instructions carefully! If you have any questions, please raise your hand and we will come to your seat.

During the whole experiment it is not allowed to talk to other participants, to use cell phones, or to launch any other programs on the computer. Disregarding any of these rules will lead to your exclusion from the experiment and from all payments.

In principle, the earnings resulting from your decisions will be paid out to you in cash at the end the experiment. Only in an exceptional case, you will receive your money later, either in cash or via a bank transfer according to which you choose. (More on that will be announced in a moment.)

On the following pages, we will describe the exact experimental procedure. 


\section{The Experiment: Your Decisions}

In this experiment you will make 85 different decisions, each between two alternatives: A and B. Each of these two alternatives is a lottery. Here is an example of such a lottery: With a probability of $50 \%$ you win $€ 9$ and with a probability of $50 \%$ you win $€ 12$. Winning probabilities and the amounts in euro that you can win will vary between decisions.

The 85 decisions are summarized in four large tables, with about 20 rows each. Each row represents one decision. The four tables will be shown to you on four subsequent decision screens.

This is a decision screen with one such table. This table only serves as an example and is, therefore, shortened to five rows.

Bitte wählen Sie in jeder Zeile eine Alternative aus.

\begin{tabular}{|c|c|c|}
\hline Alternative $\mathrm{A}$ & & Alternative B \\
\hline $4.00 €$ mit $50 \%$ oder $19.00 €$ mit $50 \%$ & Alternative $\mathrm{A} C$ Alternative $\mathrm{B}$ & $7.00 €$ mit $50 \%$ oder $23.00 €$ mit $50 \%$ \\
\hline $4.00 €$ mit $50 \%$ oder $19.00 €$ mit $50 \%$ & Alternative $\mathrm{A} C \bullet \quad$ Alternative $\mathrm{B}$ & $6.50 €$ mit $50 \%$ oder $22.50 €$ mit $50 \%$ \\
\hline $4.00 €$ mit $50 \%$ oder $19.00 €$ mit $50 \%$ & Alternative $\mathrm{A} C \boldsymbol{C}$ Alternative $\mathrm{B}$ & $6.00 €$ mit $50 \%$ oder $22.00 €$ mit $50 \%$ \\
\hline $4.00 €$ mit $50 \%$ oder $19.00 €$ mit $50 \%$ & Alternative $A \subset C$ Alternative $B$ & $5.50 €$ mit $50 \%$ oder $21.50 €$ mit $50 \%$ \\
\hline $4.00 €$ mit $50 \%$ oder $19.00 €$ mit $50 \%$ & Alternative $\mathrm{A} C \backsim$ Alternative $\mathrm{B}$ & $5.00 €$ mit $50 \%$ oder $21.00 €$ mit $50 \%$ \\
\hline
\end{tabular}

Figure C.1. Screenshot of an example choice list ("table")

that subjects were given as part of the written instructions.

Translation of the depicted table: "Please choose one alternative in each row.

Alternative A [first row:] €4.00 with $50 \%$ or $€ 19.00$ with $50 \%$

Alternative B [first row:] $€ 7.00$ with $50 \%$ or $€ 23.00$ with $50 \% "$.

Please choose whether you prefer Alternative A or B for every row by checking the respective option with your mouse. Alternative B becomes either more or less attractive when moving from the top to the bottom, depending on the table. Therefore, the respective rows are filled out automatically, as soon as you have switched from alternative A to B, or from Alternative B to A, for the first time.

As long as you have not hit the "continue" button, you can still change your decisions. Once you have made all decisions in one of the large tables, please click the "continue" button in the lower right corner of the screen. You will then see the next decision screen containing another large table.

Your payment from the experiment is determined in a two-step process: In Step 1, one of your 85 decisions (i.e., one row from one of the four tables) will be drawn randomly. This is the only decision that will affect your payment. That means you should make your decision in every single row as if it were your only decision. All decisions are drawn with the same probability (1/85).

For the drawn decision, it is determined whether you selected alternative A or B. In Step 2 the lottery you have chosen is played, determining your payment. An example: Assume decision 4 from the table shown above is drawn in Step 1. Alternative B was chosen in decision 4 . In Step 2 it is - according to the lottery-randomly determined whether you receive $€ 5.50$ or $€ 21.50$. In this example, the payoffs of $€ 5.50$ and $€ 21.50$ are equally likely (both have a probability of $50 \%$ ). 
Following those four large tables we will show you additional, smaller tables. The purpose of those smaller tables is to learn about your decisions in more detail. You will receive a more detailed description and explanation regarding these tables on your screen during the course of the experiment.

\section{Further Tasks}

Before you make your decision (as described above), there are two additional tasks to be completed. It is very important for the experiment that you make an effort to complete the tasks diligently and correctly. For each task, you will be handed out a sheet of paper containing text that you should work on. We will collect both sheets of paper at the end of the experiment. Moreover, you will receive private feedback about your performance in the two tasks on screen at the end of the experiment.

First Task You will receive a first sheet of paper containing text. Please cross out each instance of the letter " $\mathrm{e}$ " (including " $\mathrm{E}$ ") in the text. Start the task with working on the first paragraph and continue paragraph by paragraph.

You have 3 minutes to work on this task. Rather work conscientiously on few paragraphs than try to work on many paragraphs. The time remaining for the task is shown in the upper right corner of your screen.

Second Task After having finished the first task, you will receive a second sheet of paper containing text. Now you have to cross out each instance of the letter "e" according to the following set of rules:

Generally, you cross out the letter "e"; there are, however, the following exceptions:

(a) there is a vowel in the text after the letter "e", or (b) there is a vowel in the text two letters after the letter "e", or (c) there is a vowel in the text two letters in front of the letter "e".

If there is a vowel directly in front of the "e" (as, for instance, in case of "circa elf"), the "e" is to be crossed out.

In counting letters, disregard full stops, commas, hyphens, or spaces. Vowels comprise: A, Ä, E, I, O, Ö, U, Ü.

The following schematic representation summarizes the rules:

$$
--e_{--}
$$

1234

Cross out all instances of "e" in principle. Exceptions: Do not cross out the "e" if there is a vowel on position 1,3 , or 4 .

As in the first task, please start with the first paragraph and continue paragraph by paragraph.

You have 7 minutes to work on this task. Rather work conscientiously on few paragraphs than try to work on many paragraphs. The time remaining for the task is shown in the upper right corner of your screen. 
Following these two tasks, you will make the 85 decision described previously.

Second Task [Control] After having finished the first task, you will receive a second sheet of paper containing text. Please cross out each instance of the letter " $e$ " (including " $E$ ") in the text again. This is the same instruction as in the first task. As in the first task-please start with the first paragraph and continue paragraph by paragraph.

You have 7 minutes to work on this task. Rather work conscientiously on few paragraphs than try to work on many paragraphs. The time remaining for the task is shown in the upper right corner of your screen.

Following these two tasks, you will make the 85 decision described previously.

\section{Training and Comprehension Questions}

Before you start working on both tasks, we ask you to answer a few training questions regarding the decisions. Answering those questions will make it easier to acquaint yourself with the decision situation.

At the end of today's experiment-following your decisions-there are a few screens with questions and the like, before the money you earned is paid out.

In case you have any questions — now or while working on the training tasks—please raise your hand. We will come to your seat to answer your questions.

Please do not ask any questions aloud! 


\section{References}

Achtziger, Anja, Alós-Ferrer, Carlos, and Wagner, Alexander K. (2015). “Money, Depletion, and Prosociality in the Dictator Game." Journal of Neuroscience, Psychology, and Economics, 8(1), 1-14. DOI: 10.1037/npeooooo31. [12]

Allais, Maurice (1953). “Le Comportement de l'Homme Rationnel devant le Risque: Critique des Postulats et Axiomes de l'École Américaine." Econometrica, 21(4), 503-546. DOI: 10.2307/ 1907921. $[6,9,10]$

Alonso, Ricardo, Brocas, Isabelle, and Carrillo, Juan D. (2014). "Resource Allocation in the Brain." Review of Economic Studies, 81(2), 501-534. DOI: 10.1093/restud/rdto43. [7]

Alós-Ferrer, Carlos and Strack, Fritz (2014). "From dual processes to multiple selves: Implications for economic behavior." Journal of Economic Psychology, 41, 1-11. DOI: 10.1016/j.joep.2013.12. 005. [25]

Anderson, Lisa R. and Mellor, Jennifer M. (2008). "Predicting health behaviors with an experimental measure of risk preference." Journal of Health Economics, 27(5), 1260-1274. DOI: 10.1016/j. jhealeco.2008.05.011. [4]

Andersson, Ola, Tyran, Jean-Robert, Wengström, Erik, and Holm, Håkan J. (2013). “Risk Aversion Relates to Cognitive Ability: Fact or Fiction?" IFN Working Paper no. 964. Stockholm, Sweden: Research Institute of Industrial Economics. http://www.ifn.se/eng/publications/wp/2013/964. (Forthcoming in the Journal of the European Economic Association.) [15]

Barsky, Robert B., Juster, F. Thomas, Kimball, Miles S., and Shapiro, Matthew D. (1997). "Preference Parameters and Behavioral Heterogeneity: An Experimental Approach in the Health and Retirement Study." Quarterly Journal of Economics, 112(2), 537-579. DOI: 10.1162/ o03355397555280. [4]

Baumeister, Roy F., Bratslavsky, Ellen, Muraven, Mark, and Tice, Dianne M. (1998). “Ego Depletion: Is the Active Self a Limited Resource?" Journal of Personality and Social Psychology, 74(5), 1-15. DOI: 10.1037/0022-3514.74.5.1252. [4, 5, 7, 12]

Benjamin, Daniel J., Brown, Sebastian A., and Shapiro, Jesse M. (2013). “Who Is 'Behavioral'? Cognitive Ability and Anomalous Preferences." Journal of the European Economic Association, 11(6), 1231-1255. DOI: 10.1111/jeea.12055. [6, 7]

Bertrams, Alex and Dickhäuser, Oliver (2009). "Messung dispositioneller Selbstkontroll-Kapazität." Diagnostica, 55(1), 2-10. DOI: 10.1026/0012-1924.55.1.2. [18, 24]

Brocas, Isabelle and Carrillo, Juan D. (2008). “The Brain as a Hierarchical Organization." American Economic Review, 98(4), 1312-1346. DOI: 10.1257/aer.98.4.1312. [6]

Bruyneel, Sabrina D., Dewitte, Siegfried, Franses, Philip Hans, and Dekimpe, Marnik G. (2009). “I Felt Low and My Purse Feels Light: Depleting Mood Regulation Attempts Affect Risk Decision Making." Journal of Behavioral Decision Making, 22(2), 153-170. DOI: 10.1002/bdm.619. [7]

Buckert, Magdalena, Schwieren, Christiane, Kudielka, Brigitte M., and Fiebach, Christian J. (2014). "Acute stress affects risk taking but not ambiguity aversion." Frontiers in Neuroscience, 8, Article 82 (1-11). DOI: 10.3389/fnins.2014.00082. [6]

Carter, Evan C., Kofler, Lilly M., Forster, Daniel E., and McCullough, Michael E. (2015). “A Series of Meta-Analytic Tests of the Depletion Effect: Self-Control Does Not Seem to Rely on a Limited Resource." Journal of Experimental Psychology: General, 144(4), 796-815. DOI: 10.1037/ xgeooooo83. [16]

Carter, Evan C. and McCullough, Michael E. (2014). “Publication bias and the limited strength model of self-control: has the evidence for ego depletion been overestimated?" Frontiers in Psychology, 5, Article 823 (1-11). DOI: 10.3389/fpsyg.2014.00823. [8, 16, 24] 
Cohn, Alain, Engelmann, Jan, Fehr, Ernst, and Maréchal, Michel André (2015). “Evidence for Countercyclical Risk Aversion: An Experiment with Financial Professionals." American Economic Review, 105(2), 860-885. DOI: 10.1257/aer.20131314. [6]

Conte, Anna, Levati, M. Vittoria, and Nardi, Chiara (2013). “The Role of Emotions on Risk Preferences: An Experimental Analysis." Jena, Germany. http://pubdb.wiwi.uni-jena.de/pdf/wp\%5C_2013\% 5C_046.pdf. [6]

De Langhe, Bart, Sweldens, Steven, Van Osselaer, Stijn M. J., and Tuk, Mirjam (2008). "The Emotional Information Processing System is Risk Averse: Ego-Depletion and Investment Behavior." Working Paper. Erasmus Research Institute of Management (ERIM), Erasmus Universiteit Rotterdam. http://hdl.handle.net/1765/13614. [7]

Deck, Cary and Jahedi, Salar (2015). "The effect of cognitive load on economic decision making: A survey and new experiments." European Economic Review, 78, 97-119. DOI: 10.1016/j. euroecorev.2015.05.004. [6]

Dekel, Eddie, Lipman, Barton L., and Rustichini, Aldo (2009). “Temptation-Driven Preferences." Review of Economic Studies, 76(3), 937-971. DOI: 10.1111/j.1467-937X.2009.00560.x. [6]

Diamond, Peter and Kőszegi, Botond (2003). "Quasi-hyperbolic discounting and retirement." Journal of Public Economics, 87(9-10), 1839-1872. DOI: 10.1016/So047-2727(02)00041-5. [6]

Dohmen, Thomas, Falk, Armin, Huffman, David, Sunde, Uwe, Schupp, Jürgen, and Wagner, Gert G. (2011). "Individual Risk Attitudes: Measurement, Determinants, and Behavioral Consequences." Journal of the European Economic Association, 9(3), 522-550. DOI: 10.1111/j.15424774.2011.01015.x. [4]

Ebert, Sebastian and Wiesen, Daniel (2011). “Testing for Prudence and Skewness Seeking." Management Science, 57(7), 1334-1349. DOI: 10.1287/mnsc.1110.1354. [13]

Ebert, Sebastian and Wiesen, Daniel (2014). "Joint measurement of risk aversion, prudence, and temperance." Journal of Risk and Uncertainty, 48(3), 231-252. DOI: 10.1007/s11166-014-9193-0. $[5,13]$

Eeckhoudt, Louis and Schlesinger, Harris (2006). “Putting Risk in Its Proper Place." American Economic Review, 96(1), 280-289. DOI: 10.1257/000282806776157777. [5, 13]

Falk, Armin and Zimmermann, Florian (2014). "Consistency as a Signal of Skills." Working paper. University of Bonn, Germany, and University of Zurich, Switzerland. https://sites.google. com/site/econflorianzimmermann/ConsistencySkills4.o.pdf. (Forthcoming in Management Science.) [12]

Fischbacher, Urs (2007). "z-Tree: Zurich toolbox for ready-made economic experiments." Experimental Economics, 10(2), 171-178. DOI: 10.1007/s10683-006-9159-4. [18]

Freeman, Nicholas and Muraven, Mark (2010). "Self-Control Depletion Leads to Increased Risk Taking." Social Psychological and Personality Science, 1(2), 175-181. DOI: 10.1177/ 1948550609360421. [7, 8, 12]

Friehe, Tim and Schildberg-Hörisch, Hannah (2014). "Crime and Self-Control Revisited: Disentangling the Effect of Self-Control on Risk and Social Preferences." IZA Discussion Paper. Bonn, Germany: University of Bonn. http://ftp.iza.org/dp8109.pdf. [7]

Fudenberg, Drew and Levine, David K. (2006). “A Dual-Self Model of Impulse Control." American Economic Review, 96(5), 1449-1476. DOI: 10.1257/aer.96.5.1449. [4-11, 23-27, 31]

Fudenberg, Drew and Levine, David K. (2011). "Risk, Delay, and Convex Self-Control Costs." American Economic Journal: Microeconomics, 3(3), 34-68. DOI: 10.1257/mic.3.3.34. [4, 6, 8-10, 23, 24, 26, 32]

Fudenberg, Drew and Levine, David K. (2012). “Timing and Self-Control." Econometrica, 80(1), 1-42. DOI: 10.3982/ECTA9655. [4, 6, 7, 9, 23] 
Fudenberg, Drew, Levine, David K., and Maniadis, Zacharias (2014). "An approximate dual-self model and paradoxes of choice under risk." Journal of Economic Psychology, 41, 55-67. DOI: 10.1016/j.joep.2013.02.007. [4-10, 21, 23, 25-28]

Greiner, Ben (2004). "An Online Recruitment System for Economic Experiments." In Forschung und wissenschaftliches Rechnen - Beiträge zum Heinz-Billing-Preis 2003, edited by Kurt Kremer and Volker Macho. GWDG-Bericht. Gesellschaft für wissenschaftliche Datenverarbeitung Göttingen, 79-93. http://www.gwdg.de/fileadmin/inhaltsbilder/Pdf/Publikationen/ GWDG-Berichte/gwdg-bericht-63.pdf. [18]

Guiso, Luigi, Sapienza, Paola, and Zingales, Luigi (2014). “Time Varying Risk Aversion.” Working paper. University of Chicago, USA, et al. http:/ / faculty.chicagobooth.edu/luigi.zingales/papers/ research/Time\%7B\%5C_\%7DVarying\%7B\%5C_\%7DRisk\%7B\%5C_\%7DAversion.pdf. [6]

Gul, Faruk and Pesendorfer, Wolfgang (2007). "Harmful Addiction." Review of Economic Studies, 74(1), 147-172. DOI: 10.1111/j.1467-937X.2007.00417.x. [6]

Hagger, Martin S. and Chatzisarantis, Nikos L. D. (2014). "It is premature to regard the ego-depletion effect as 'Too Incredible'." Frontiers in Psychology, 5(Article 298), 1-2. DOI: 10.3389/fpsyg.2014. 00298. [16]

Hagger, Martin S., Wood, Chantelle, Stiff, Chris, and Chatzisarantis, Nikos L. D. (2010). “Ego Depletion and the Strength Model of Self-Control: A Meta-Analysis." Psychological Bulletin, 136(4), 495525. DOI: 10.1037/aoo19486. [4, 7, 8, 12, 16, 17, 19, 24]

Harbaugh, William T., Krause, Kate, and Vesterlund, Lise (2010). “The Fourfold Pattern of Risk Attitudes in Choice and Pricing Tasks." Economic Journal, 120(545), 595-611. DOI: 10.1111/j.14680297.2009.02312.x. [11, 19]

Hauge, Karen Evelyn, Brekke, Kjell Arne, Johansson, Lars-Olof, Johansson-Stenman, Olof, and Svedsäter, Henrik (2014). "Keeping others in our mind or in our heart? Distribution games under cognitive load." Working Papers in Economics, No. 600. Göteborg, Sweden: University of Gothenburg. http://hdl.handle.net/2077/36279. [18]

Heidhues, Paul and Kőszegi, Botond (2009). "Futile Attempts at Self-Control." Journal of the European Economic Association, 7(2/3), 423-434. DOI: 10.1162/JEEA.2009.7.2-3.423. [6]

Holt, Charles A. and Laury, Susan K. (2002). "Risk Aversion and Incentive Effects." American Economic Review, 92(5), 1644-1655. DOI: 10.1257/000282802762024700. [14]

Kandasamy, Narayanan, Hardy, Ben, Page, Lionel, Schaffner, Markus, Graggaber, Johann, Powlson, Andrew S., Fletcher, Paul C., Gurnell, Mark, and Coates, John (2014). “Cortisol shifts financial risk preferences." Proceedings of the National Academy of Sciences USA, 111(9), 3608-3613. DOI: 10.1073/pnas.1317908111. [6]

Kimball, Miles S., Sahm, Claudia R., and Shapiro, Matthew D. (2008). “Imputing Risk Tolerance From Survey Responses." Journal of the American Statistical Association, 103(483), 1028-1038. DOI: 10.1198/016214508000000139. [4]

Kostek, John and Ashrafioun, Lisham (2014). "Tired Winners: The Effects of Cognitive Resources and Prior Winning on Risky Decision Making." Journal of Gambling Studies, 30(2), 423-434. DOI: 10.1007/s10899-013-9365-x. [7]

Kouchaki, Maryam and Smith, Isaac H. (2014). "The Morning Morality Effect: The Influence of Time of Day on Unethical Behavior." Psychological Science, 25(1), 95-102. DOI: 10.1177/ 0956797613498099. [18]

Laibson, David (1997). “Golden Eggs and Hyperbolic Discounting." Quarterly Journal of Economics, 112(2), 443-477. DOI: 10.1162/003355397555253. [6]

Loewenstein, George and O'Donoghue, Ted (2005). “Animal Spirits: Affective and Deliberative Processes in Economic Behavior." Working paper. Carnegie Mellon University and Cornell 
University. https://odonoghue.economics.cornell.edu/files/2015/10/will5_05-227fjlg.pdf. [4$6,8,11,21,23-25]$

MacLeod, Colin M. (1991). "Half a century of research on the Stroop effect: an integrative review." Psychological Bulletin, 109(2), 163-203. http://doi.apa.org/psycinfo/1991-14380-001. [16]

Mukherjee, Kanchan (2010). “A Dual System Model of Preferences Under Risk." Psychological Review, 117(1), 243-255. DOI: 10.1037/a0017884. [6, 11, 25]

Muraven, Mark and Slessareva, Elisaveta (2003). "Mechanisms of Self-Control Failure: Motivation and Limited Resources." Personality and Social Psychology Bulletin, 29(7), 894-906. DOI: 10. 1177/0146167203029007008. [13]

Ozdenoren, Emre, Salant, Stephen W., and Silverman, Dan (2012). "Willpower and the Optimal Control of Visceral Urges." Journal of the European Economic Association, 10(2), 342-368. DOI: 10.1111/j.1542-4774.2010.01050.x. [7]

Rabin, Matthew (2000). "Risk Aversion and Expected-Utility Theory: A Calibration Theorem." Econometrica, 68(5), 1281-1292. DOI: 10.1111/1468-0262.00158. [6]

Schulreich, Stefan, Gerhardt, Holger, and Heekeren, Hauke R. (forthcoming). “Incidental Fear Cues Increase Monetary Loss Aversion." Emotion, DOI: 10.1037/emooooo124. [6]

Schulreich, Stefan, Heussen, Yana G., Gerhardt, Holger, Mohr, Peter N. C., Binkofski, Ferdinand C., Koelsch, Stefan, and Heekeren, Hauke R. (2014). "Music-evoked incidental happiness modulates probability weighting during risky lottery choices." Frontiers in Psychology, 4, Article 981 (1-17). DOI: 10.3389/fpsyg.2013.00981. [6]

Stigler, George J. and Becker, Gary S. (1977). "De Gustibus Non Est Disputandum." American Economic Review, 67(2), 76-90. http://www.jstor.org/stable/1807222. [6]

Stojić, Hrvoje, Anreiter, Michael R., and Carrasco Martinez, José A. (2013). "An Experimental Test of the Dual Self Model." Working paper. Barcelona, Spain: Universitat Pompeu Fabra. http: //www.econ.upf.edu/ hstojic/Stojic_Anreiter_Martinez_2013.pdf. [7]

Stroop, J. Ridley (1935). "Studies of interference in serial verbal reactions." Journal of Experimental Psychology, 18(6), 643-662. DOI: 10.1037/hoo54651. [16-18]

Tangney, June P., Baumeister, Roy F., and Boone, Angie Luzio (2004). "High Self-Control Predicts Good Adjustment, Less Pathology, Better Grades, and Interpersonal Success." Journal of Personality, 72(2), 271-324. DOI: 10.1111/j.0022-3506.2004.00263.x. [18, 24]

Thaler, Richard H. and Shefrin, Hersh M. (1981). “An Economic Theory of Self-Control." Journal of Political Economy, 89(2), 392-406. DOI: 10.1086/260971. [9, 26]

Tversky, Amos and Kahneman, Daniel (1992). "Advances in prospect theory: Cumulative representation of uncertainty." Journal of Risk and Uncertainty, 5(4), 297-323. DOI: 10.1007/BFo0122574. [11]

Unger, Alexander and Stahlberg, Dagmar (2011). "Ego-Depletion and Risk Behavior." Social Psychology, 42(1), 28-38. DOI: 10.1027/1864-9335/aoooo40. [7]

Watson, David and Clark, Lee Anna (1999). "The PANAS-X: Manual for the Positive and Negative Affect Schedule-Expanded Form." Online Manual. University of lowa. http:/ / ir.uiowa.edu/cgi/ viewcontent.cgi?article=1011\&context=psychology_pubs. [18]

Wheeler, S. Christian, Briñol, Pablo, and Hermann, Anthony D. (2007). "Resistance to persuasion as self-regulation: Ego-depletion and its effects on attitude change processes." Journal of Experimental Social Psychology, 43(1), 150-156. DOI: 10.1016/j.jesp.2006.01.001. [12] 